Watada et al.

\title{
1 Age-dependent ribosomal DNA variations and their effect on \\ 2 cellular function in mammalian cells
}

3 (Short title: Age-dependent ribosomal DNA variations)

4

5

6

9 IInstitute for Quantitative Biosciences (IQB), 2 Department of Biological Sciences, University of

10 Tokyo 1-1-1 Yayoi, Bunkyo-ku, Tokyo 113-0032, JAPAN

11 3Collaborative Research Institute for Innovative Microbiology, University of Tokyo, 1-1-1

12 Yayoi, Bunkyo-ku, Tokyo 113-0032, JAPAN

13 4From the Graduate School of Pharmaceutical Sciences, Tohoku University, Sendai 980-8578,

14 JAPAN

15

16

17 5Corresponding author:

18 Tel: $+81-3-5841-7861$

19 Fax: $+81-3-5841-8472$

20

21

22

23

24

25

26

27 tables). 
Watada et al.

\section{Abstract}

2 The ribosomal RNA gene, which consists of tandem repetitive arrays (rDNA repeat), is

3 one of the most unstable regions in the genome. The rDNA repeat in the budding yeast

4 is known to become unstable as the cell ages. However, it is unclear how the rDNA

5 repeat changes in ageing mammalian cells. Using quantitative analyses, we identified

6 age-dependent alterations in rDNA copy number and levels of methylation in mice. The

7 degree of methylation and copy number of rDNA from bone marrow cells of 2-year-old

8 mice were increased by comparison to 4-week-old mice in two mouse strains,

$9 \mathrm{BALB} / \mathrm{cA}$ and C57BL/6. Moreover, the level of pre-rRNA transcripts was reduced in

10 older BALB/cA mice. We also identified many sequence variations among the repeats

11 with two mutations being unique to old mice. These sequences were conserved in

12 budding yeast and equivalent mutations shortened the yeast chronological lifespan. Our

13 findings suggest that rDNA is also fragile in mammalian cells and alterations within this

14 region have a profound effect on cellular function.

16 Author Summary

17 The ribosomal RNA gene (rDNA) is one of the most unstable regions in the genome

18 due to its tandem repetitive structure. rDNA copy number in the budding yeast increases

19 and becomes unstable as the cell ages. It is speculated that the rDNA produces an

20 "aging signal" inducing senescence and death. However, it is unclear how the rDNA

21 repeat changes during the aging process in mammalian cells. In this study, we attempted

22 to identify the age-dependent alteration of rDNA in mice. Using quantitative single cell

23 analysis, we show that rDNA copy number increases in old mice bone marrow cells. By

24 contrast, the level of ribosomal RNA production was reduced because of increased

25 levels of DNA methylation that represses transcription. We also identified many

26 sequence variations in the rDNA. Among them, three mutations were unique to old

27 mice and two of them were found in the conserved region in budding yeast. We then

28 established a yeast strain with the old mouse-specific mutations and found this 
Watada et al.

1 shortened the lifespan of the cells. These findings suggest that rDNA is also fragile in

2 mammalian cells and alteration to this region of the genome affects cellular senescence.

3

\section{Introduction}

5

6 The genome, which comprises the complete set of genetic information in an organism,

7 is sensitive to damage from environmental factors such as exposure to ultraviolet

8 radiation. Damage to the genome is efficiently repaired by a highly organized repair

9 system (1)(2). Nonetheless, some damage is not properly repaired leading to mutations,

10 which may include rearrangements such as deletions and amplifications. In addition,

11 mutations can also arise from errors introduced during DNA replication. These

12 mutations accumulate during successive cell divisions to induce cellular senescence.

13 However, the underlying mechanism linking accumulation of mutations to senescence

14 is not well understood.

16 Damage to DNA tends to accumulate at fragile sites in the genome (3). In the budding

17 yeast, Saccharomyces cerevisiae, the ribosomal RNA gene (rDNA) is known to be a

18 fragile site that is related to cellular senescence (4). Eukaryotic rDNA is made up of

19 repetitive tandem arrays, which in the case of the budding yeast comprises $\sim 150$ rDNA

20 copies located on chromosome XII. However, copies of these repeats are readily lost by

21 homologous recombination. Because the cell requires a huge number of ribosomes,

22 accounting for $\sim 60 \%$ of total cellular protein, a gene amplification system is needed to

23 compensate for these losses. As a result, rDNA copy number frequently varies leading

24 to an unstable genomic region (for review, see (5)). In terms of rDNA gene

25 amplification in budding yeast, the replication fork blocking protein Fob1 works as a

26 recombination inducer (6). Fob1 associates with the replication fork barrier (RFB) site,

27 inhibiting the replication process and inducing a DNA double-strand break that triggers gene amplification/recombination (7)(8)(9). 
Watada et al.

2 Intriguingly, fobl mutants have a stable rDNA copy number, and lifespan is extended

3 by $\sim 60 \%$ compared to the wild-type strain (10)(11). An important factor in suppressing

4 rDNA copy-number change is Sir2, an NAD+-dependent protein deacetylase that is

5 conserved across all kingdoms of life. Interestingly, sir 2 mutants of $S$. cerevisiae

6 display increased unequal sister chromatid recombination, and the rDNA copy number

7 frequently changes (7)(12). Moreover, the lifespan of the sir2 mutant is shortened to

8 approximately half that of the wild-type strain (13)(14). Taken together, these

9 observations suggest that rDNA instability (i.e. frequent copy number alteration) is

10 related to senescence (15).

12 In mammals, the rDNA structure is similar to that of yeast. However, the intergenic

13 spacer sequence (IGS) in mammalian cells is larger than in yeast (Figure 1A) and is an

14 unstable region of the genome (16). The connection between aging and rDNA has been

15 suggested in several studies of tissues from dog, mouse and human (17)(18)

16 (19)(20)(21). Werner syndrome is a human premature aging disease. The rDNA of cells

17 derived from patients with Werner syndrome display an increased level of noncanonical

18 arrangements (22). In the hematopoietic stem cells of mice, replication stress

19 accumulates in the rDNA and cellular functional activity declines with age (23).

20 However, there is still a paucity of observations how rDNA changes during senescence.

22 Here, we compared the genome of young and old mice, and identified differences in

23 rDNA stability, methylation and transcription status. We also identified two mutations

24 in rDNA that are specific to old mice. Moreover, these sequences are conserved in

25 budding yeast rDNA. Interestingly, equivalent mutations in the budding yeast rDNA

26 shortened their chronological lifespan. These findings suggest that the rDNA is also

27 fragile in a mammalian cell and mutation of these sites affects cellular function. 
Watada et al.

\section{$1 \quad$ Results}

2

\section{3 rDNA copy number is increased in older mice}

4 Because the rDNA copy number readily changes, each cell may have a different copy

5 number. Therefore, we initially measured the rDNA copy number in a single cell by

6 quantitative real-time PCR (qPCR). In this strategy, we determined rDNA copy number

7 of RPE1 (Human Retinal Pigment Epithelial cell) to obtain a standard curve by Droplet

8 Digital PCR (ddPCR, BIORAD). In brief, a fixed amount of RPE1 DNA was digested

9 into small fragments, diluted and fractionated into droplets. The dilution factor ensured

10 that each droplet contains just one DNA fragment. Each droplet was then subjected to

11 PCR and the number of positive droplets with an rDNA fragment counted. The ratio of

12 the number of positive to negative droplets gives the absolute copy number of rDNA.

13 Using this method, RPE1 cells were found to have 330 rDNA copies (See Materials \&

14 Methods for detail). The RPE1 DNA was then used as a control in determining the

15 mouse rDNA copy number in a single cell by qPCR. Initially, we ensured the accuracy

16 of the assay using one and two bone marrow cells, and one, two and four RPE1 cells to

17 measure the rDNA copy number by qPCR. As anticipated, the rDNA copy number

18 increased linearly with cell number (Figure S1).

20 Bone marrow cells were isolated from young (four-week old) and old (two-year old)

$21 \mathrm{BALB} / \mathrm{cA}$ and C57BL/6 mice. Specifically, four young and five old BALB/cA mice

22 (males), and four young (two males, two females) and four old (two males and two

23 females) C57BL/6 mice were tested. The cells were separated into a 96-well plate using

24 a FACS machine and subjected to qPCR to determine the rDNA copy number. The

25 results are shown in Figure 1B. We first noticed that the average rDNA copy numbers

26 (dotted lines) are quite different in these two strains. In the young mice, they were 471

27 (BALB/cA ) and 1,025 (C57BL/6) per cell, that is, C57BL/6 has more than double. The

28 ratio $(1,025 / 471)$ was 2.18 . To confirm the difference, we also estimated rDNA copy 
Watada et al.

1 number using publicly available whole genome sequencing data in NCBI. As shown in

2 Figure S2, three mice data in each strain were analyzed and their average copy numbers

3 were determined as $642(\mathrm{BALB} / \mathrm{cA})$ and 1,412 (C57BL/6) per cell. The ratio

$4(1,412 / 642)$ was 2.20 . Therefore, we think the difference of rDNA copy number in the

5 two strains in our single cell analysis is reasonable and the analysis works well.

6

7 In terms of aging effect on the rDNA copy number, in both mouse strains, the average

8 was increased in the older mice. We also calculated the coefficient of variation

9 (S.D./mean) in individual cells, which indicates the rate of copy number variation in

10 each mouse cell normalized by the average. The values obtained for the old mice were

11 smaller than those for the young mice (see Discussion). These findings indicate that

12 rDNA copy number increases in most old mice cells while the copy number variation

13 decreases.

14

15 We also tested the copy number alteration in old mice by Southern blot analysis. In this assay, DNA was isolated from mouse bone marrow cells and double digested with

17 BamHI/NdeI restriction endonucleases before being subjected to agarose gel

18 electrophoresis (Figure 2). The probe for the Southern blot was designed to recognize

19 the 28S rRNA gene in the $4 \mathrm{~kb}$ BamHI-NdeI restricted fragment. However, some of the

20 rDNA copies had a second BamHI site (BamHI-2) in the $4 \mathrm{~kb}$ fragment (Figure 2A),

21 resulting in the detection of two bands (Figure 2B, top). For BALB/cA, the upper bands

22 (4 kb) appear stronger than the lower bands in the old mice, suggesting a relative loss of

23 BamHI-2 sites within rDNA. To normalize the results, a single copy gene (SWI5) was

24 also detected using a specific probe (Figure $2 \mathrm{~B}$, middle). The intensities of the bands

25 were measured, and the values plotted (Figure. 2B, bottom). This analysis showed the

26 intensity of the $4 \mathrm{~kb}$ BamHI - NdeI fragment for BALB/cA mice increased relative to

27 the other fragments. Taken together, the data showed the rDNA copy number tended to 
Watada et al.

1 increase with age although the difference was not as marked as in the qPCR analysis

2 (See Discussion).

3

$4 \quad$ rDNA transcription levels are decreased in the older mice

5

6 The previous qPCR and Southern analysis showed the copy number of the rDNA

7 tended to increase in older mice. We therefore speculated that the increased copy

8 number of rDNA might result in an elevated level of rDNA transcripts (rRNA). To test

9 this hypothesis, RNA was isolated using cells derived from young and old mice and the

10 level of 28S rRNA measured by RT qPCR. The values were normalized against the

11 transcripts of three housekeeping genes, Actb (actin, beta), B2M (beta-2 microglobulin),

12 and GAPDH (glyceraldehyde-3-phosphate dehydrogenase). The results are shown in

13 Figure 3B. Although there was a tendency for the young mice cells to have more 28S

14 rRNA, the difference was not significant except for the results normalized against B2M.

15 It is possible that the housekeeping genes are also affected by age. In addition, most of

16 the $28 \mathrm{~S}$ rRNA are thought to be included in the ribosomes that abundantly accumulate

17 in the cell. Therefore, we measured newly synthesized pre-matured 45S rRNA using a

18 probe that recognizes the promoter region and then calculated the ratio of matured to

19 pre-matured rRNA. As shown in Figure 3C, in BALB/c, the newly synthesized rRNA

20 ratio was reduced in the old mice. However, this difference was not as obvious in the

21 C57BL/6 mice.

22

23 Transcription inactivation of rRNA gene in C57BL/6 mice was confirmed using the

24 psoralen crosslinking method (24). Psoralen intercalates into non-nucleosomal rDNA

25 copies that are actively transcribed more efficiently than those that are transcriptionally

26 inactive. Therefore, using this method, we can estimate the proportion of active rDNA

27 copies. Cells are treated with psolaren, UV crosslinked and the DNA isolated. After

28 digestion with AflIII the DNA was subjected to agarose gel electrophoresis. The results 
Watada et al.

1 are shown in Figure 4. The upper and lower bands correspond to transcribed (active)

2 and non-transcribed (inactive) rDNA copies, respectively (Figure 4B). Band intensities

3 were measured, and the values plotted (Figure 4C). The ratio of active to non-active

4 rDNA was less in the old cells than in the young cells. These findings suggest that

5 rDNA transcription is reduced in the older mice.

6

$7 \quad$ rDNA is more highly methylated in the older mice

8

9 Transcription is known to be affected by DNA methylation (25). Recently, it was

10 reported that the methylation rate of rDNA increases in an age-dependent manner in

11 both mouse and human (26). Therefore, we speculated that increased methylation of

12 rDNA might reduce the transcription level in older mice. To test this hypothesis, DNA

13 from the old and young mice was digested using a methylation sensitive enzyme SacII

14 and the restriction pattern analyzed (27). As shown in Figure 5B, in the absence of

15 SacII, two bands (4.0 and $2.4 \mathrm{~kb}$, highlighted by arrowheads) were observed after

16 BamHI-NdeI digestion (refer to Figure 2B). However, after SacII digestion most of

17 these bands disappeared in the young mice. By contrast, the same analysis of DNA from

18 old mice showed faint bands were still detectable (Figure 5B). The signal intensities of

19 undigested and digested bands were measured, and the ratios calculated. As a loading

20 control, a single gene SWI5 was also detected. The values of signal intensity were then

21 plotted (Figure 5B, lower panel). The ratios of methylation in the old mice were

22 increased except for the \#2* mouse. The same assay was performed in C57BL/6 strain

23 and similar results were obtained (Figure 5C). These results confirmed that rDNA in the

24 old mice is more methylated than in the young mice. Taken together, our findings

25 suggest DNA methylation causes the reduced level of transcription of rDNA.

\section{There is sequence variation in rDNA of young and old mice}


Watada et al.

1 Finally, we determined the rDNA sequence in the young and old mice. Bone marrow

2 cells, including hematopoietic stem cells that produce leukocytes, erythrocytes and

3 platelets, are known to divide frequently. Thus, we speculated that mutations in the

4 older mice cells accumulate and affect the function of the ribosome causing aging

5 phenomena, such as slow growth and reduced viability. DNA from young and old mice

6 was isolated and the 18S, 5.8S and 28S genes PCR amplified for analysis by deep

7 sequencing. All of the reads were aligned and compared with the mouse reference

8 sequences (28) to identify mutation sites. The results are shown in Figure 6A-C. The

9 "mutation rate" is the ratio of mutations identified in the sequences to the total reads.

10 Thus, a "mutation rate of $1(100 \%)$ " means the sequence is different from the reference

11 sequence. If the mutation rate is $0.5(50 \%)$, half of the rDNA copies display a variation

12 at that site. As a control, we also analyzed a housekeeping gene ATP5b (ATP synthase

13 gene) (Figure 6D).

15 As shown in Figure 6, the overlapping black and yellow marks indicate the mutation

16 rates in the young and old mice cells were similar. The average mutation rates in both

17 young and old mice cells were similar (Figure S3 and S4E). Thus, any age-dependent

18 alteration of rDNA sequence was not immediately apparent. Nonetheless, the average

19 mutation rate of $28 \mathrm{~S}$ rDNA (BA:0.00341, BL:0.00321) was higher than that of $18 \mathrm{~S}$

20 rDNA $(0.00236,0.00222)$ and much higher than ATP5b and 5.8S (0.00054 0.00066).

21 Indeed, sequence variation among copies of $28 \mathrm{~S}$ rDNA has been reported previously

22 (29). All of the high rate variations in $28 \mathrm{~S}$ and $18 \mathrm{~S}$ rDNA were found in DNA from

23 both young and old mice (Figure 6).

25 For the purpose of identifying old mice-specific mutations, we searched for variations

26 with a mutation rate of $>0.0028(0.28 \%)$, which was equivalent to the maximum value

27 for the control gene (ATP5b). The threshold value is the maximum apparent artificial

28 mutation rate caused by PCR amplification or other errors. Within this range, we 
Watada et al.

1 identified three old mice-specific mutations in the old BALB/cA strain (Table 1). By

2 contrast, no old mice-specific mutations were identified in the C57BL/6 strain. Indeed,

3 no old mice-specific variations were found after increasing the number of mice that

4 were sequenced (Figure S4).

5

6 Accuracy of the sequencing data was verified by analyzing variation of the BamHI

7 recognition sequence that was detected in Figure 2 and Figure 5. The anticipated

8 variation in the sequencing data corresponding to the BamHI site (GGATCC) in both

9 mouse strains was observed together with the changes seen in the old BALB/cA mice

10 (0.25 to 0.685$)$ (Table S1). Thus, the sequencing data correlate with the Southern

11 analysis in which the intensities of the upper bands increased in the old BALB/cA mice

12 (Figure 2B).

13

14 The old mouse-specific mutations of rDNA affect yeast ribosomal function

16 To analyze the relationship between rDNA variation and function, we summed up the

17 mutation rates in $20 \mathrm{bp}$ windows and plotted the values (Figure 7). In the graph, several

18 variations, or "hotspots", were identified over the 28S rDNA. Interestingly, most of the

19 hotspots (highlighted in yellow) were located in the non-conserved regions between

20 mouse and budding yeast rDNA (red line, top). These observations suggest that most of

21 the variations are present in the non-functional region of the 28S rRNA gene.

23 We also mapped the positions of the three old mouse-specific mutations identified in

24 the BALB/cA mice to yeast 25S rDNA. Interestingly, two sites (3291 and 4614) were

25 plotted in the conserved region between mouse and yeast, suggesting they might be

26 located in the functional domains in the rRNA. One approach to study the consequence

27 of these mutations is to examine their impact in yeast. Thus, we generated budding

28 yeast strains carrying the corresponding mutations in the 25S rDNA. For specific 
Watada et al.

1 expression of the mutated rDNA, we used a yeast strain without rDNA in the

2 chromosome ( $r d n \Delta \Delta$ strain) (30). The strain initially carried a helper rDNA plasmid,

3 which was then shuffled with plasmids containing mutations in the $25 \mathrm{~S}$ region. The

4 plasmid-borne mutated rDNA thus became the sole source of rRNA. Strains with either

5 plasmid-derived wild-type rDNA, A2131G (mouse A3291G), or A3295G (mouse

$6 \quad$ A4614G) mutated rDNA showed comparable cell growth in both solid and liquid

7 medium. To test the relationship between these mutations and senescence, we measured

8 the chronological lifespan by calculating survival rates every two days after the cells

9 entered the stationary phase. As shown in Figure 8, one of the mutations (A3295G)

10 lowered the proportion of surviving cells at all time points from day 5 onwards,

11 indicating a shortened chronological lifespan. By contrast, another mutant (A2131G)

12 showed similar survival rates to that of the wild-type yeast until day 15, but then the

13 rate dropped on day 17 . These observations suggest that although both mutations

14 identified in the old mouse rDNA support cell growth in yeast, they may be harmful

15 during chronological aging, particularly A3295G (mouse A4614G).

\section{Discussion}

19 The rDNA has the following unique features that make it possible to monitor age-

20 dependent alterations in the genome. Firstly, because rDNA is a highly repetitive and

21 recombinogenic region it is easy to assess instability by monitoring alterations in copy

22 number. Secondly, as approximately half of the rDNA copies are not transcribed

23 (24)(31), these repetitive non-transcribed regions are targets for both methylation (32)

24 and mutation (33). Indeed, our analyses detected alterations in copy number and

25 methylation level in old mice, as well as putative old mouse-specific mutations.

27 In terms of rDNA copy number alteration observed in old mice, the results from

28 literature reports are contradictory (18). Copy number alteration itself is commonly 
Watada et al.

1 observed by many researchers, but in some reports the number goes up and in others it

2 goes down. Moreover, copy number alteration has also been observed in tissues (18).

3 Some of these discrepancies may arise from problems related to hybridization during

4 Southern blot analysis. The repetitive nature of the DNA combined with the high level

5 of bound proteins from the nucleolus may affect the detection efficiency. Indeed, our

6 results showed that although the rDNA copy number in old mice increased as detected

7 by single cell analysis by qPCR, this increase was not obvious by Southern blot analysis

8 in either of the two mouse strains (Figure 1 and Figure 2). For budding yeast, rDNA

9 copies in the old cells dramatically increases ( $\sim 10$ times) as extra chromosomal rDNA

10 circles (ERC) and their presence is a big burden on the cells because ERCs consume

11 factors that are required for chromosome maintenance (34)(35). Therefore, the copious

12 amount of ERC is thought to be a passive accelerator of cellular aging. In the case of

13 mammals, this age-dependent increase of rDNA copies is not as dramatic $(<2$ times,

14 Figure 1). As such, the extra rDNA copies in mammals may not in itself reduce

15 lifespan.

17 In terms of genome instability, it may be possible to connect age-dependent changes in rDNA to the aging process. To address this issue, we previously established a strain of S. cerevisiae with reduced replication initiation activity only in the rDNA (36). Because ERC cannot replicate, there is no ERC accumulation. However, the lifespan of the strain

21 was shortened, and rDNA stability was reduced in the strain. We speculated that extended travel of DNA polymerase, due to reduced replication initiation, induces DNA

23 replication stress, such as fork arrest and damage, leading to genome instability. These

24 findings suggested rDNA instability and/or damage itself is an aging signal that

25 shortens lifespan (5). From this viewpoint, yeast and mammalian rDNA may play

26 similar roles in terms of aging by acting as a large fragile site for disseminating an aging

27 signal (5). Indeed, the replication fork blocking activity that causes rDNA

28 recombination in the budding yeast is also present in mammalian rDNA (for a review 
Watada et al.

1 see (37)(38)). A similar fork arrest induces rDNA instability to promote senescence by

2 distributing the aging signal. Further studies are required to investigate this hypothesis.

3

4 In the single cell analysis, we found that the copy number of rDNA increased and the

5 variation decreased in older cells. As far as we are aware, there is no previous report

6 showing alteration of rDNA copy number at the single cell level. One possible reason to

7 explain the reduced variation phenotype in the old cells is that the number of stem cells

8 for bone marrow goes down with age. Indeed, it is known that the number of

9 the hematopoietic stem cells in the bone marrow gradually decreases during the process

10 of aging (39). As bone marrow cells are produced from the stem cells, the variation of

11 rDNA copies is reduced.

12

13 The relationship between rDNA methylation and senescence has been discussed in

14 previous reports $(25)(26)$. The present results are consistent with these previous studies

15 in showing that rDNA is more highly methylated in older mice (Figure 5). DNA

16 methylation is known to repress transcriptional activity (25). Indeed, the ratio of $45 \mathrm{~S}$ to

$1728 \mathrm{~S}$ transcripts reduced in the old BALB/cA mice. The underlying reason for the age-

18 dependent increase in methylation has not been elucidated. However, repetitive non-

19 coding elements, such as retrotransposons, are known targets for DNA methylation

20 enzymes (32). In addition, rDNA is subject to DNA damage and has a high GC content,

21 which are known to be related to age-dependent methylation (40)(41). Hence, a similar

22 mechanism may recognize the repetitive rDNA as a target for methylation. Moreover, in

23 terms of the relationship between reduced rDNA transcription and increased copy

24 number in old cells, one possible explanation is that cells can compensate for lowering

25 the production of rRNA by elevated copies of rDNA to enable them to survive. As a

26 result, the rDNA copy number in the old mice is more than in the young mice. 
Watada et al.

1 We anticipated more mutations in the older mice because there are many untranscribed

2 non-canonical rDNA copies (22) and hematopoietic stem cells are subject to DNA

3 replication stress (23). The untranscribed copies can accumulate mutations and

4 replication stress increases DNA damage. However, the mutation rate in old mice was

5 similar to that in young mice (Figure S3 and S4E). Therefore, cells should have an

6 effective repair system and/or mechanism to avoid mutation accumulation such as gene

7 conversion for homogenization (33). In this study, we identified three such mutations in

8 the old mice. Although these mutations were present only in the old mice, it is not

9 known whether they occurred during the aging process. Moreover, it is not known

10 whether the rDNA copies with the mutation are actually transcribed or not. Thus, these

11 mutations may not be related to senescence in the mice. Nonetheless, we found that two

12 equivalent mutations in the budding yeast permitted cell growth, but one of the

13 mutations (A3295G) apparently shortened the chronological lifespan. These findings

14 indicate that the mutated rDNA, when present as the only source of rRNA, is

15 transcribed and can support the essential functions of the ribosome, but viability during

16 aging is negatively impacted, at least in yeast. Therefore, one could infer that if such

17 harmful mutations accumulate in the rDNA repeats during the course of successive cell

18 divisions, they may cause defects in the ribosomal and cellular functions to induce

19 senescence.

21 In this study, we used two mice strains, BALB/cA and C57BL/6, for the analyses and

22 they showed slightly different results. The rDNA copy number in C57BL/6 is twice as

23 large as that in BALB/cA. Age-dependent alterations in the copy number, transcription

24 and methylation levels were more prominent in BALB/cA. The mutation rate in

$25 \mathrm{BALB} / \mathrm{cA}$ was also higher than that in C57BL/6 and we were only able to identify

26 specific mutations in older mice for the BALB/cA strain. These observations suggest

27 that BALB/cA has a stronger aging phenotype than C57BL/6. Indeed, of the two mouse

28 strains, BALB/cA is known to be more susceptible to carcinogens. Thus, BALB/cA 
Watada et al.

1 may have a less efficient DNA repair system and a more unstable rDNA region,

2 resulting in an enhanced level of senescence.

3

4

\section{$5 \quad$ Materials \& Methods}

6

\section{Ethics statement}

8 All experiments were approved by the Animal Experiment Ethics Committees at the

9 Institute of Molecular and Cellular Biosciences, University of Tokyo (Exp \# 0210).

10 Experiments were performed in precise accordance with the manual provided by the

11 Life Science Research Ethics and Safety Committee, University of Tokyo.

Mice

14 Young mice (4 week-old, BALB/cAJc1 and C57BL/6JJc1) were purchased from CLEA Japan, Inc. (Tokyo, Japan) The old mice (approximately 2 year-old, BALB/cAJc1 and C57BL/6JJc1) were from this institute. For Figure S4, both the 8 week-old and 200 week-old C57BL/6JJcl mice were purchased from CLEA Japan, Inc.

\section{Determination of rDNA copy number in single cells}

Bone marrow cells $(2 \times 107)$ were isolated, washed three times with $5 \mathrm{ml}$ PBS and then 1 $\mathrm{ml}$ of $0.005 \%$ propidium iodide (PI) (P4864; Sigma-Aldrich, St Louis, MO) was added.

22 Each cell was sorted using a high speed cell sorter (MoFlo XDR; BECKMAN COULTER, Brea, CA) into a 96-well plate with qPCR buffer [SYBR Premis Ex TaqTM (Tli RHaseH Plus)] (RR420A; TAKARA, Tokyo, Japan) with 0.4 uM primers (Table S2) and 0.24\% Nonidet P-40 (Darmanis et al., 2017). For qPCR, the plate was applied to a Thermal Cycler Dice® Real Time System II (TP900; TAKARA) with the

27 following amplification conditions; $98^{\circ} \mathrm{C}$ for $30 \mathrm{sec}$ then 40 cycles of $95^{\circ} \mathrm{C}$ for $5 \mathrm{sec}$, $60^{\circ} \mathrm{C}$ for $30 \mathrm{sec}$. The standard curve was generated by serial dilution of DNA from 
Watada et al.

1 determined by Droplet Digital PCR (ddPCR). Briefly, 5 ng RPE1 DNA was digested

2 with HpaII (NEB, Ipswich, MA), suspended in ddPCR mixture [ddPCR Supermix (No

3 dUTP) (1863023; Bio-Rad, Hercules, CA), target primers/probe (FAM), reference

4 primers/probe (VIC, TaqMan ${ }^{\mathrm{TM}}$ Copy Number Reference Assay, human, RNase P,

5 4403326; ThermoFisher, Waltham, MA)] and applied to а Х200тм Droplet Generator

6 (1864002; Bio-Rad). Each droplet was collected into a 96-well plate [twin.tec semi-

7 skirted 96-well plate, 951020362; Eppendorf, Enfield, CT] and detected by PCR using

8 the following conditions; $95^{\circ} \mathrm{C}$ for $10 \mathrm{~min}$ followed by 40 cycles of $94^{\circ} \mathrm{C}$ for $30 \mathrm{sec}$,

$960^{\circ} \mathrm{C}$ for $1 \mathrm{~min}$ and then $98^{\circ} \mathrm{C}$ for $10 \mathrm{~min}$. The signal was detected by a QX200TM

10 Droplet Reader and the number of positive droplets calculated using QuantaSoftTM

11 Software (1864003; Bio-Rad). On average a RPE1 cell had 330 rDNA copies.

13 Southern blot analysis to detect rDNA

14 For Southern blot analysis $150 \mathrm{ng}$ of mouse DNA was digested with 10 units of BamHI-

15 HF (NEB, Figure 2 and 5), NdeI (NEB, Figure 2 and 5) and SacII (NEB, Figure 5)

16 overnight at $37^{\circ} \mathrm{C}$. The digested DNA was resolved on a $0.8-1.0 \%$ agarose gel (in

17 1xTAE) and blotted onto a filter. The $28 \mathrm{~S}$ and SWI5 were detected on the same filter

18 using PCR amplified probes with specific primers (Table S3). For the psoralen

19 crosslinking assay, 2 x 107 bone marrow cells were suspended in $8 \mathrm{ml}$ Opti-MEM ${ }_{\circledast} \mathrm{I}$

20 Reduced Serum Medium (ThermoFisher) and divided into two $6 \mathrm{~cm}$-diameter dishes. A

$21200 \mu \mathrm{l}$ solution of psoralen in methanol $(200 \mu \mathrm{g} / \mathrm{ml}$, Sigma-Aldrich) was added to each

22 dish and only methanol to the control dish. Each of the dishes were placed on ice for 5

23 min and crosslinked using UV-A for 4 min (7 cm apart from the UV light). This UV

24 exposure and psoralen addition cycle was repeated four times. Cells were then scraped

25 and collected by centrifugation (1,800 rpm, $5 \mathrm{~min})$, and the DNA isolated. A $500 \mathrm{ng}$

26 aliquot of DNA was digested with 20 units of AflIII (NEB) overnight at $37^{\circ} \mathrm{C}$ and

27 subjected to Southern blot analysis (1\% agarose gel in 1xTAE, $60 \mathrm{~V}, 18 \mathrm{hr}$ ). The gel 
Watada et al.

1 was then exposed to UV (4000 J/cm2 x 100) using a UV Stratalinker to reverse the

2 crosslinking(42), (43), (44).

3

4 RT qPCR

5 Bone marrow cells ( $1 \times 107)$ were washed with $5 \mathrm{ml}$ PBS twice and the total RNA was

6 isolated using a RNeasy Mini Kit (74104; Qiagen, Hilden, Germany). The solution was

7 subsequently treated with DNase I (79254; Qiagen). The RNA was reverse transcribed

8 to DNA by ReverTra Ace qPCR RT Master Mix (FSQ-201; TOYOBO, Tokyo, Japan)

9 and the DNA solution (0.2 ng) was applied to qPCR using SYBR Premis Ex TaqTM

10 (Tli RHaseH Plus) (RR420A; TAKARA). For normalization, housekeeping genes, Actb

11 (actin, beta), GAPDH (glyceraldehyde-3-phosphate dehydrogenase) and B2M (beta-2

12 microglobulin) were also examined. The sequences of the primers $(0.4 \mu \mathrm{M}$ each $)$ are

13 given in Table S2. The PCR conditions were as follows; 40 cycles of $95^{\circ} \mathrm{C}$ for $5 \mathrm{sec}$,

$1460^{\circ} \mathrm{C}$ for $30 \mathrm{sec}$.

rDNA sequence analysis

17 rDNA coding regions (18S, 5.8S and 28S) were amplified by PCR. The PCR mix

18 included $20 \mathrm{ng}$ of rDNA or $150 \mathrm{ng}$ of ATP5b gene genomic DNA in a 40 ul reaction 19 mixture (0.2 mM dNTPs, $1.5 \mathrm{mM} \mathrm{MgSO}_{4}, 0.25 \mu \mathrm{M}$ primers, $1 \times$ PCR Buffer for KOD-

20 Plus-Neo, 0.8 U KOD-Plus-Neo). The sequences of the primers are listed in Table S2.

21 The PCR cycle conditions were as follows for $18 \mathrm{~S}$ rRNA: $94^{\circ} \mathrm{C}$ for $2 \mathrm{~min}, 25$ cycles of

$2298^{\circ} \mathrm{C}$ for $10 \mathrm{sec}, 60^{\circ} \mathrm{C}$ for $30 \mathrm{sec}, 68^{\circ} \mathrm{C}$ for $90 \mathrm{sec}$, then $68^{\circ} \mathrm{C}$ for $15 \mathrm{sec}$; for $5.8 \mathrm{~S} \mathrm{rRNA}$ :

$2394^{\circ} \mathrm{C}$ for $2 \mathrm{~min}, 25$ cycles of $98^{\circ} \mathrm{C}$ for $10 \mathrm{sec}, 60^{\circ} \mathrm{C}$ for $30 \mathrm{sec}, 68^{\circ} \mathrm{C}$ for $30 \mathrm{sec}$, then

$2468^{\circ} \mathrm{C}$ for $15 \mathrm{sec}$; for $28 \mathrm{~S}$ rRNA: $94^{\circ} \mathrm{C}$ for $2 \mathrm{~min}, 25$ cycles of $98^{\circ} \mathrm{C}$ for $10 \mathrm{sec}, 68^{\circ} \mathrm{C}$ for

$253 \mathrm{~min}$, then $68^{\circ} \mathrm{C}$ for $15 \mathrm{sec}$; for ATP5b: $94^{\circ} \mathrm{C}$ for $2 \mathrm{~min}, 25$ cycles of $98^{\circ} \mathrm{C}$ for $10 \mathrm{sec}$,

$26 \quad 68^{\circ} \mathrm{C}$ for $30 \mathrm{sec}$, then $68^{\circ} \mathrm{C}$ for $15 \mathrm{sec}$. The PCR products were purified by Nucleospin ${ }^{\circledR}$

27 Gel and PCR Clean-up (740609-250; TAKARA). 
Watada et al.

1 Purified DNA was sonicated using a Covaris M220 instrument (Covaris, Woburn, MA)

2 to $150-200$ bp long fragments. The DNA was purified using a QIA quick PCR

3 Purification kit (QIAGEN), and the library generated with a NEB Next Ultra II DNA

4 Library Prep Kit for Illumina (NEB). The quality of the library was checked using an

5 Agilent 2100 Bioanalyzer (Agilent High Sensitivity DNA kit). Sequencing was

6 performed by HiSeq 2500 (Illumina, Hiseq SR Cluster kit v4, Hiseq SBS Kit v4, 50

7 cycles). The sequence data was mapped on the reference sequence (GenBank

8 BK000964) using Bowtie 2 (version 2.3.3.1), and the base frequency at each position

9 was calculated to obtain the mutation rate (substitution, insertion and deletion) on a

10 Galaxy platform (https://usegalaxy.org/). High-throughput sequencing data have been

11 uploaded to NCBI Sequence Read Archive database under accession code

12 PRJNA636244 (https://www.ncbi.nlm.nih.gov/sra).

14 Yeast strains

15 Yeast strains expressing plasmid-borne rDNA with distinct mutations were constructed 16 by plasmid shuffling. In brief, an rDNA depletion strain NOY986 (MATa ade2-1 ura3-1 17 trp1-1 leu2-3,112 his3-11,15 can1-100 rdn $\Delta 4:$ :hisG (30) carrying a high-copy-number $18 \mathrm{rDNA} / \mathrm{URA} 3+$ plasmid was first transformed with a rDNA/LEU2+ plasmid containing 19 mutation at A3295(mouse A4614) or A2131(mouse A3291) within the 25S region.

20 Strains that had lost the former URA3+ plasmid were then positively selected on SC-

21 LEU plates containing 5-FOA.

\section{Yeast chronological lifespan analysis}

24 Yeast cells were streaked on a 2\%-glucose YP plate from a glycerol stock and incubated at $30^{\circ} \mathrm{C}$ for 3 days. A single colony was grown at $30^{\circ} \mathrm{C}$ overnight in $2 \mathrm{ml} \mathrm{SC}$ medium containing $2 \%$ glucose, shaking at $200 \mathrm{rpm}$. The culture was diluted with fresh $2 \%$ -

27 glucose SC medium to an optical density of 0.1 (OD 600 units) to give a day 0 culture of $20 \mathrm{ml}$. Starting at day 3 and every 2 days, a $100 \mu \mathrm{l}$ aliquot of the culture was removed and diluted with sterile water to prepare a 1:10,000 dilution. The dilution was spread onto a $2 \%$-glucose YP plate and incubated at $30^{\circ} \mathrm{C}$ for 3 days. The number of colony- 
Watada et al.

1 forming units (CFU) was scored and normalized with that of the day 3 culture to

2 establish the survival rate. All experiments were performed in biological triplicates.

3

\section{Acknowledgement}

5 We thank Drs Yusuke Yamazumi and Tetsu Akiyama for gifting old mice and for

6 technical advice on how to isolate bone marrow cells. We thank Drs. Yufuko Akamatsu,

7 Mariko Sasaki, Tetsushi Iida, Chihiro Horigome and all other members of the

8 Laboratory of Genome Regeneration for helpful discussions. This research was

9 supported by AMED under Grant Number JP20gm1110010 to TK and T.I., and in part

10 by grants-in-aid for Scientific Research [17H01443 to T.K.] from the Japan Society for

11 the Promotion of Science (JSPS).

12

\section{References}

15 1. Sancar A, Lindsey-Boltz LA, Ünsal-Kaçmaz K, Linn S. Molecular mechanisms 16 of mammalian DNA repair and the DNA damage checkpoints. Annu Rev

17 Biochem. 2004;73(1):39-85.

18 2. Dana Branzei MF. Regulation of DNA Repair Throughout the Cell Cycle. Nat 19 Rev Mol Cell Biol . 2008;4:297-308.

20 3. Durkin SG, Glover TW. Chromosome fragile sites. Annu Rev Genet. $21 \quad 2007 ; 41: 169-92$.

22 4. Kobayashi T. A new role of the rDNA and nucleolus in the nucleus - rDNA instability maintains genome integrity. Vol. 30, BioEssays. Wiley Online Library; 2008. p. 267-72.

5. Kobayashi T. Regulation of ribosomal RNA gene copy number and its role in modulating genome integrity and evolutionary adaptability in yeast. 68, Cellular and Molecular Life Sciences. Springer; 2011. p. 1395-403. Fob1p and Inhibits the Replication Fork. Mol Cell Biol. 2003;23(24):9178-88. 
Watada et al.

17 Kobayashi T, Horiuchi T, Tongaonkar P, Vu L, Nomura M. SIR2 regulates recombination between different rDNA repeats, but not recombination within individual rRNA genes in yeast. Cell. 2004;117(4):441-53.

4 8. Burkhalter MD, Sogo JM. rDNA enhancer affects replication initiation and mitotic recombination: Fob1 mediates nucleolytic processing independently of replication. Mol Cell. 2004;15(3):409-21.

7 9. Weitao T, Budd M, Hoopes LLM, Campbell JL. Dna2 helicase/nuclease causes replicative fork stalling and double-strand breaks in the ribosomal DNA of Saccharomyces cerevisiae. J Biol Chem. 2003;278(25):22513-22.

10. Defossez P-A, Prusty R, Kaeberlein M, Lin S-J, Ferrigno P, Silver PA, et al. Elimination of Replication Block Protein Fob1 Extends the Life Span of Yeast Mother Cells. Mol Cell [Internet]. 1999;3(4):447-55.

11. Takeuchi Y, Horiuchi T, Kobayashi T. Transcription-dependent recombination and the role of fork collision in yeast rDNA. Genes Dev. 2003;17(12):1497-506.

12. Kobayashi T, Ganley ARD. Recombination regulation by transcription-induced cohesin dissociation in rDNA repeats. Science (80- ). 2005;309(5740):1581-4.

13. Kaeberlein M, McVey M, Guarente L. The SIR2/3/4 complex and SIR2 alone promote longevity in Saccharomyces cerevisiae by two different mechanisms. Genes Dev. 1999;13(19):2570-80.

14. Saka K, Ide S, Ganley ARD, Kobayashi T. Cellular senescence in yeast is regulated by rDNA noncoding transcription. Curr Biol. 2013;23(18):1794-8.

15. Kobayashi T. Ribosomal RNA gene repeats, their stability and cellular senescence. Vol. 90, Proceedings of the Japan Academy Series B: Physical and Biological Sciences. The Japan Academy; 2014. p. 119-29.

16. Stults DM, Killen MW, Williamson EP, Hourigan JS, Vargas HD, Arnold SM, et al. Human rRNA gene clusters are recombinational hotspots in cancer. Cancer Res. 2009;69(23):9096-104.

17. Johnson R, Strehler BL. Loss of genes coding for ribosomal RNA in ageing brain cells. Nature. 1972;240(5381):412-4.

18. Gaubatz JW, Cutler RG. Age-related differences in the number of ribosomal rna genes of mouse tissues. Gerontology. 1978;24(3):179-207. 
Watada et al.

1 19. Zafiropoulos A, Tsentelierou E, Linardakis M, Kafatos A, Spandidos DA. Preferential loss of 5S and 28S rDNA genes in human adipose tissue during ageing. Int J Biochem Cell Biol. 2005;37(2):409-15.

20. Strehler BL, Chang M, Johnson LK. Loss of hybridizable ribosomal DNA from human post-mitotic tissues during aging: I. Age-dependent loss in human myocardium. Mech Ageing Dev. 1979;11(5-6):371-8.

21. Strehler BL, Chang MP. Loss of hybridizable ribosomal DNA from human postmitotic tissues during aging: II. Age-dependent loss in human cerebral cortex Hippocampal and somatosensory cortex comparison. Mech Ageing Dev. 1979;11(5-6):379-82.

22. Caburet S, Conti C, Schurra C, Lebofsky R, Edelstein SJ, Bensimon A. Human ribosomal RNA gene arrays display a broad range of palindromic structures. Genome Res. 2005;15(8):1079-85.

23. Flach J, Bakker ST, Mohrin M, Conroy PC, Pietras EM, Reynaud D, et al. Replication stress is a potent driver of functional decline in ageing haematopoietic stem cells. Nature. 2014;512(7513):198-202.

24. Dammann R, Lucchini R, Koller T, Sogo JM. Chromatin structures and transcription of rDNA in yeast Saccharomyces cerevisiae. Nucleic Acids Res. 1993;21(10):2331-8.

25. D'Aquila P, Montesanto A, Mandalà M, Garasto S, Mari V, Corsonello A, et al. Methylation of the ribosomal RNA gene promoter is associated with aging and age-related decline. Aging Cell. 2017;16(5):966-75.

26. Wang M, Lemos B. Ribosomal DNA harbors an evolutionarily conserved clock of biological aging. Genome Res. 2019;29(3):325-33.

27. Nelson PS, Papas TS, Schweinfest CW. Restriction endonuclease cleavage of 5methyl-deoxycytosine hemimethylated DNA at high enzyme-to-substrate ratios. Nucleic Acids Res. 1993;21(3):681-6.

28. Grozdanov P, Georgiev O, Karagyozov L. Complete sequence of the 45-kb mouse ribosomal DNA repeat: Analysis of the intergenic spacer. Genomics. 2003;82(6):637-43.

29. Parks MM, Kurylo CM, Dass RA, Bojmar L, Lyden D, Vincent CT, et al. Variant ribosomal RNA alleles are conserved and exhibit tissue-specific expression. Sci Adv. 2018;4(2):eaao0665. 
Watada et al.

30. Wai HH, Vu L, Oakes M, Nomura M. Complete deletion of yeast chromosomal rDNA repeats and integration of a new rDNA repeat: use of rDNA deletion strains for functional analysis of rDNA promoter elements in vivo. Nucleic Acids Res. 2000;28(18):3524-34.

31. French SL, Osheim YN, Cioci F, Nomura M, Beyer AL. In Exponentially Growing Saccharomyces cerevisiae Cells, rRNA Synthesis Is Determined by the Summed RNA Polymerase I Loading Rate Rather than by the Number of Active Genes. Mol Cell Biol. 2003;23(5):1558-68.

32. Beisel C, Paro R. Silencing chromatin: Comparing modes and mechanisms. Vol. 12, Nature Reviews Genetics. Nature Publishing Group; 2011. p. 123-35.

33. Ganley ARD, Kobayashi T. Monitoring the rate and dynamics of concerted evolution in the ribosomal DNA repeats of saccharomyces cerevisiae using experimental evolution. Mol Biol Evol. 2011;28(10):2883-91.

34. Neurohr GE, Terry RL, Sandikci A, Zou K, Li H, Amon A. Deregulation of the G1/S-phase transition is the proximal cause of mortality in old yeast mother cells. Genes Dev. 2018;32(15-16):1075-84.

35. Morlot S, Song J, Léger-Silvestre I, Matifas A, Gadal O, Charvin G. Excessive rDNA Transcription Drives the Disruption in Nuclear Homeostasis during Entry into Senescence in Budding Yeast. Cell Rep. 2019;28(2):408-422.e4.

36. Ganley ARD, Ide S, Saka K, Kobayashi T. The Effect of Replication Initiation on Gene Amplification in the rDNA and Its Relationship to Aging. Mol Cell. 2009;35(5):683-93.

37. Dalgaard JZ, Godfrey EL, MacFarlane RJ. Eukaryotic Replication Barriers: How. Why and Where Forks Stall. DNA Replication-Current Adv. 2011;269304.

38. Akamatsu Y, Kobayashi T. The Human RNA Polymerase I Transcription Terminator Complex Acts as a Replication Fork Barrier That Coordinates the Progress of Replication with rRNA Transcription Activity. Mol Cell Biol. 2015;35(10):1871-81.

39. Nijnik A, Woodbine L, Marchetti C, Dawson S, Lambe T, Liu C, et al. DNA repair is limiting for haematopoietic stem cells during ageing. Nature. 2007;447(7145):686-90. 
Watada et al.

1 40. Kirkwood TBL. Understanding the odd science of aging. Vol. 120, Cell. Elsevier; 2005. p. 437-47.

3 41. Fraga MF, Agrelo R, Esteller M. Cross-talk between aging and cancer: The epigenetic language. In: Annals of the New York Academy of Sciences. Wiley Online Library; 2007. p. 60-74.

42. Udugama M, Sanij E, Voon HPJ, Son J, Hii L, Henson JD, et al. Ribosomal DNA copy loss and repeat instability in ATRX-mutated cancers. Proc Natl Acad Sci U S A. 2018;115(18):4737-42.

43. Stefanovsky V, Moss T. Regulation of rRNA synthesis in human and mouse cells is not determined by changes in active gene count. Cell Cycle. 2006;5(7):735-9.

44. Conconi A, Widmer RM, Koller T, Sogo JM. Two different chromatin structures coexist in ribosomal RNA genes throughout the cell cycle. Cell. 1989;57(5):75361.

\section{Figure legends}

Figure 1. rDNA copy number and coefficient of variation in individual cells

(A) Structure of rDNA in mouse. One unit of rDNA is $\sim 43 \mathrm{~kb}$, composed of the $45 \mathrm{~S}$ pre-rRNA gene and intergenic spacer. $45 \mathrm{~S}$ pre-rRNA is subsequently processed into three mature rRNAs (18S, 5.8S and 28S). (B) rDNA copy numbers were measured in young (4 week-old) and old (2 year-old) mice. (Upper) rDNA copy number in single cells were measured by qPCR and plotted. The copy number was determined using RPE1 as a standard (see Materials \& Methods). The X-axis shows the identification numbers (ID\#) of individual mice used to isolate the bone marrow cells. The dotted lines are the average values of the mice. The green dots are the average of two independent qPCR experiments from each mouse and the error bars indicate the range.

27 (Lower) Plots of coefficient of variation (S.D. was divided by the average) for each mouse. 
Watada et al.

1 (A) Position of the probe for Southern blot analysis in (BC) and recognition sites for

2 BamHI and NdeI are shown. (BC) Detection of relative rDNA copy number. (Top

3 panel) Southern analysis for rDNA copy number. DNA was digested with BamHI and

4 NdeI. Upper bands (4 kb) come from rDNA units without BamHI-2 site and lower

5 bands $(2.4 \mathrm{~kb})$ from rDNA units with BamHI-2 site. (Middle panel) Detection of SWI5

6 gene as a loading control. A single copy gene SWI5 was detected on the same filter

7 used in the upper panel. (Bottom panel) Relative amount of rDNA copy number. The

8 band intensities of rDNA were normalized by those of SWI5 and the values are relative

9 to the average of rDNA values in the four young mice. The blue dots show the results

10 from the upper band intensities of rDNA and the red dots are the results from the lower

11 bands. ID\# is the identification number of individual mice that were used to isolate the

12 bone marrow cells (Figure 1). p values are shown at the bottom of the panel. n.s. is "not

13 significant".

Figure 3. rDNA transcripts in old and young bone marrow cells

(A) Positions of the primer sets for qPCR to measure rDNA transcripts (pre 45S and 28S rRNA). (B) Amount of 28S rRNA normalized by transcripts of the three housekeeping genes (GAPDH, B2M and Actb). The values are the average of four independent experiments and the error bars are S.D. The values are relative to those of young cells. $p$ value is shown in case it is significant $(\mathrm{p}<0.05)$. (C) Ratio of the pre 45S rRNA to $28 \mathrm{~S}$ rRNA. The values are the average of four independent experiments and the error bars are S.D. The values are relative to those of young cells. $p$ value is shown. "n.s." is "not significant".

Figure 4. Ratio of active and inactive rDNA copies in old and young cells

Psoralen crosslinked rDNA was digested with AflIII and band retardation assessed after

27 electrophoresis. (A) Recognition sites of AflIII and position of the probe for (B). (B)

28 Southern blot analysis to detect the psoralen crosslinked rDNA by mobility retardation 
Watada et al.

1 in young and old mice. Transcription "active" rDNA efficiently intercalates psoralen,

2 which retards migration during gel electrophoresis. ID \# is the identification number of

3 the mice (same as Figure 2B). (C) Ratio of active to inactive rDNA copies. Band

4 intensities of (B) were measured and the ratio of active to inactive rDNA calculated.

5 The error bars are S.D. The $\mathrm{p}$ value is shown.

6

7 Figure 5. rDNA methylation in old and young bone marrow cells

8 rDNA methylation was detected by digestion with a methylation sensitive enzyme

9 SacII. (A) Position of the probe for Southern blot analysis in (BC) and recognition sites

10 for BamHI and SacII. (BC) Ratio of methylated rDNA copies in young and old mice.

11 (Top panel) Southern analysis to detect the ratio of undigested band by SacII. The

12 positions of undigested bands are indicated by arrowheads on the left-hand side of the

13 panels. (Middle panel) Detection of the SWI5 gene as a loading control. A single copy

14 gene SWI5 was detected on the same filter used in the upper panel. (Bottom panel)

15 Analysis of rDNA that failed to digest with SacII. The signal intensities of the

16 undigested rDNA (SacII+) and non-digested (SacII-) bands were measured and the

17 ratios plotted. The black dots show the results for the lower bands (black arrowhead, in

18 the Top panel) and the blue dots are for the upper bands (blue arrowhead in the Top

19 panel). ID\# is the identification number of individual mice that were used to isolate the

20 bone marrow cells (same as Figure 2). p values are calculated from the average of

21 young and old mice.

22

Figure 6. rDNA sequence variation in young and old mice

24 The rDNA sequences from two old and two young mice were determined and compared

25 to the reference sequence. Mutation rates were then calculated at each nucleotide position. (A) 28S rRNA gene, (B) 18S rRNA gene (C) 5.8S rRNA gene and (D) ATP5b

27 gene. Non-coding regions are not shadowed. Mutation rate is the difference from the reference sequence. Ave. is the average mutation rate. 
Watada et al.

1

2 Figure 7. Hotspot of variation in the $28 \mathrm{~S}$ rDNA

3 Mapping of hotspots of variation in mouse 28S. (Upper panel) Alignment of mouse 28S

4 and budding yeast 25S rRNA genes. The gray boxes are conserved regions in the two

5 species and the red lines are mouse unique regions. (Lower panel) Variation frequency

6 in the 28S rRNA gene. The mutation rates were summed (more than 0.0028 was picked

7 up, Figure 6A) every $20 \mathrm{bp}$ and then plotted. Data from two mice were used in each

8 graph. The yellow boxes represent mouse specific non-conserved regions.

9

10

11 Two old mouse-specific mutations in the 28S rRNA gene were introduced into the

12 budding yeast 25S rRNA gene and the chronological lifespans of the yeast measured.

13 Lifespans in the yeast strains with A2131G (left panel) and A3295G mutations in the

14 25S rRNA gene. The values are the average of nine experiments.

15

Table 1. The positions of old mouse specific mutations in BALB/cA.

17 The values refer to the mutation rates. Position 3094 is not conserved in yeast rDNA.

\section{Supporting information}

21 Supporting figure and table legends

22
RPE1 and right panel: mouse bone marrow cell.

\section{Figure S1. Accuracy in single cell analysis}

rDNA copy numbers of one, two and four cells were measured by qPCR. rDNA copy number in RPE1 determined by digital PCR was used as the standard (Materials \& Methods). In all, 12 samples for RPE1 and 36 samples for bone marrow cells were tested (dots). The horizontal bars are the average and vertical bars are S.D. Left panel: 
Watada et al.

\section{Figure S2. Estimated rDNA copy number from database}

2 rDNA copy numbers of BALB/cA (BALB/c 1-3) and C57BL/6 (B6J 1-3) mice were

3 estimated by reanalysis of publicly available whole genome sequencing data. rDNA

4 copy number estimation by whole genome sequencing data were performed as follows.

5 Fastq files obtained from NCBI SRA (PRJNA41995, PRJNA386034) were mapped

6 against mouse whole genome and rDNA sequence using Bowtie2, and the fraction of

7 rDNA reads among all mapped reads were used to calculate the copy numbers.

9 Figure S3. Mutation rates of young and old mice rDNA

10 Average mutation rates in the rDNA were calculated. (A) BALB/cA. young m3: young 11 male 3, young $\mathrm{f1}$ : young female 1, old $\mathrm{m} 3$ : old male 3, old $\mathrm{m} 4$ : old male 4 . The same 12 mice were used for Figure 6. (B) C57BL/6. young m1; young male 1, young f1: young 13 female 1, old $\mathrm{m} 1$ : old male 1, old f1: old female 1. The same mice were used for Figure 14 6. Mutation rates that are more than 0.9 were not used because they are different from 15 the reference sequences.

Figure S4. rDNA sequence variation in young and old C57BL/6 mice

18 rDNA sequences from three old (old 1-old 3) and three young (young1-young3) mice $19(\mathrm{C} 57 \mathrm{BL} / 6)$ were determined and compared to the reference sequence. The calculated 20 mutation rates at each nucleotide position was determined as for Figure 6. (ABC) Old 21 1-3 mice were compared with young 1 mouse. (A) 28S rRNA gene, (B) 18S rRNA gene and (C) 5.8S rRNA gene, (D) Three young mice and (E) Average of mutation rates. Non-coding regions are shadowed. Ave. is the average mutation rate. Mutation rate is the difference from the reference sequence as for Figure S3.

Table S1. Sequence variation at BamHI recognition sequences in young and old mice.

28 Mutation rates of BamHI sites in young and old BALB/cA mice. (Upper panel) original 29 BamHI sequence and its mutated version. (Lower panel) Mutation rates of BamHI sites. 30 Ave. is the average sum of the mutation rates. 
bioRxiv preprint doi: https://doi.org/10.1101/2020.07.10.196840; this version posted July 10, 2020. The copyright holder for this preprint (which was not certified by peer review) is the author/funder, who has granted bioRxiv a license to display the preprint in perpetuity. It is made available under aCC-BY 4.0 International license.

Watada et al.

1 Table S2. Primer list. 
A

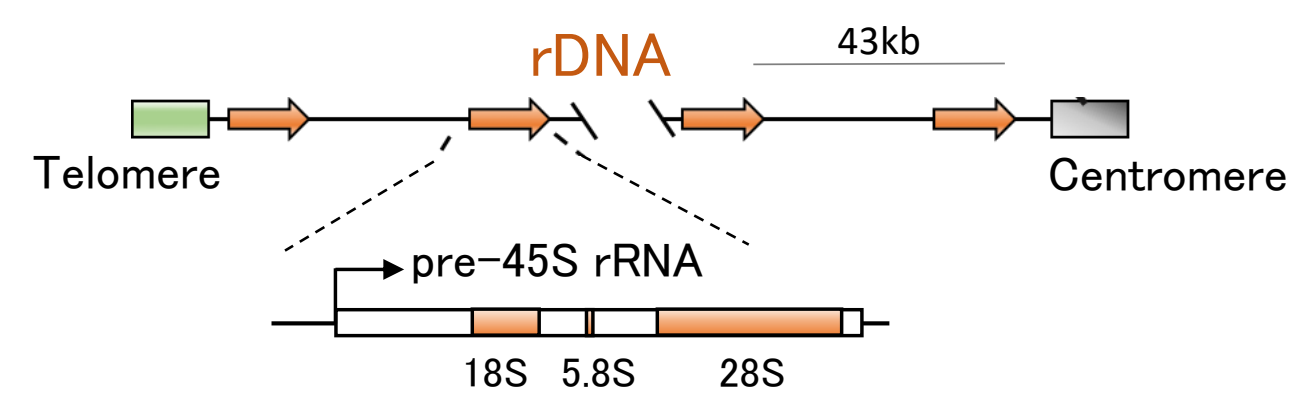

B
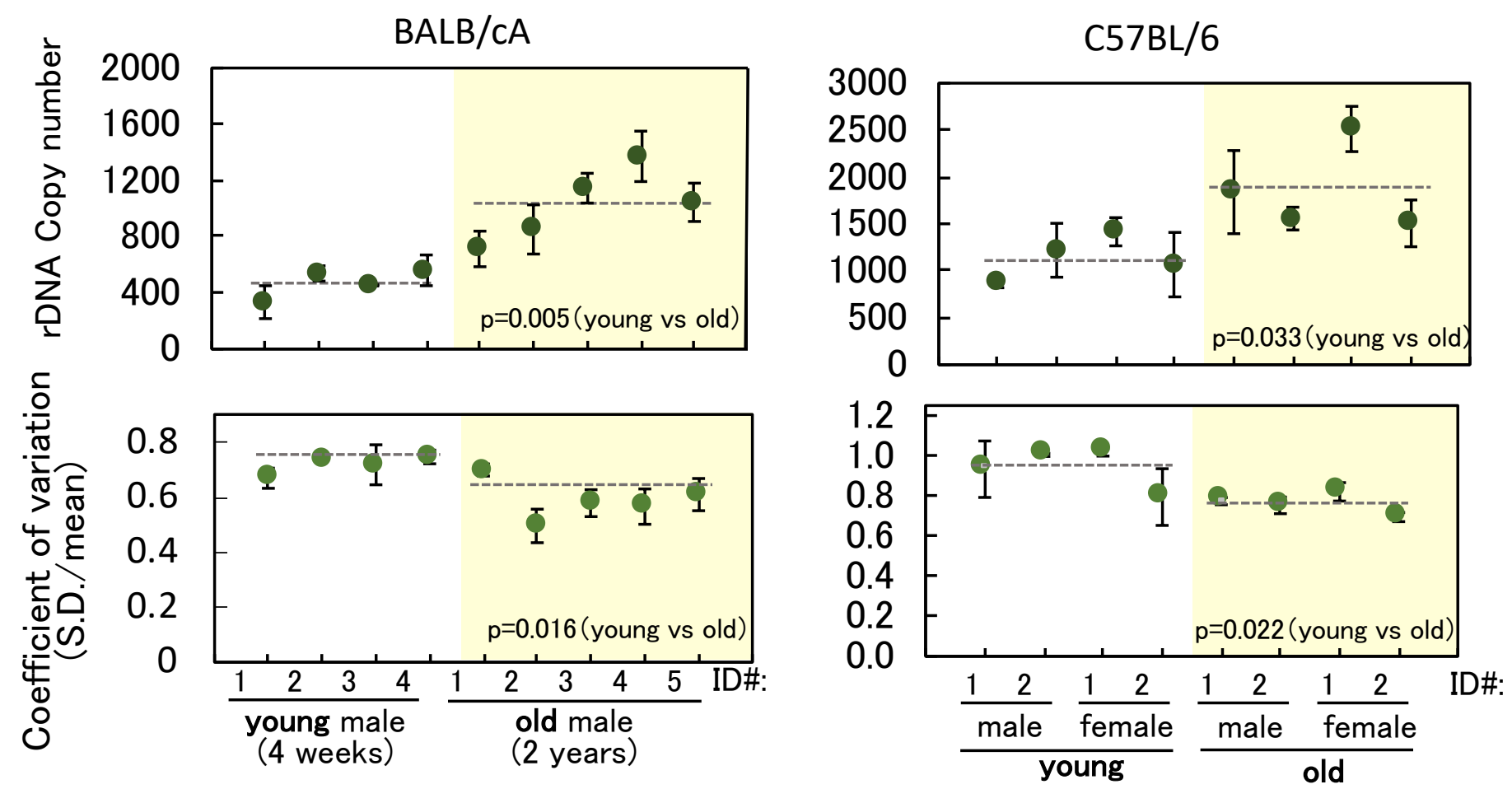

Fig.1 rDNA copy number and coefficient of variation in individual cells 
A

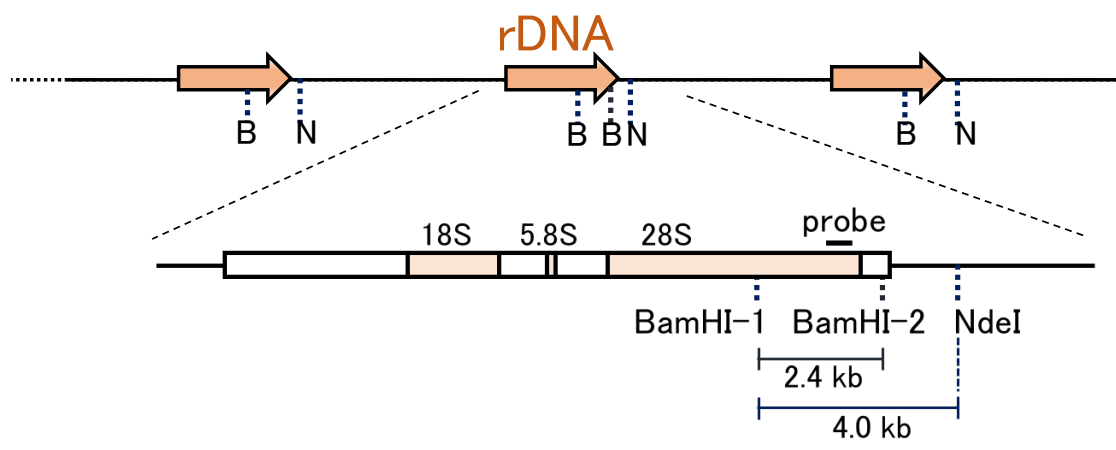

B

$\mathrm{BALB} / \mathrm{CA}$

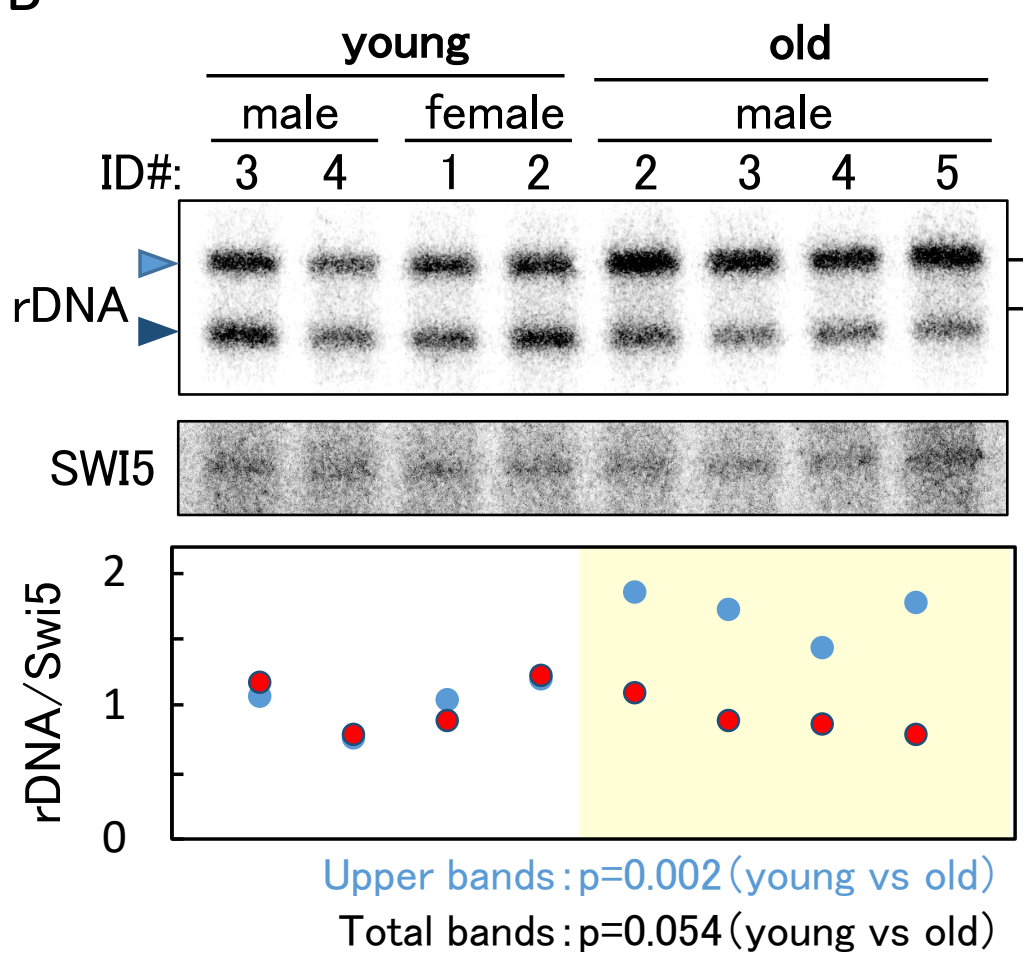

C57BL/6

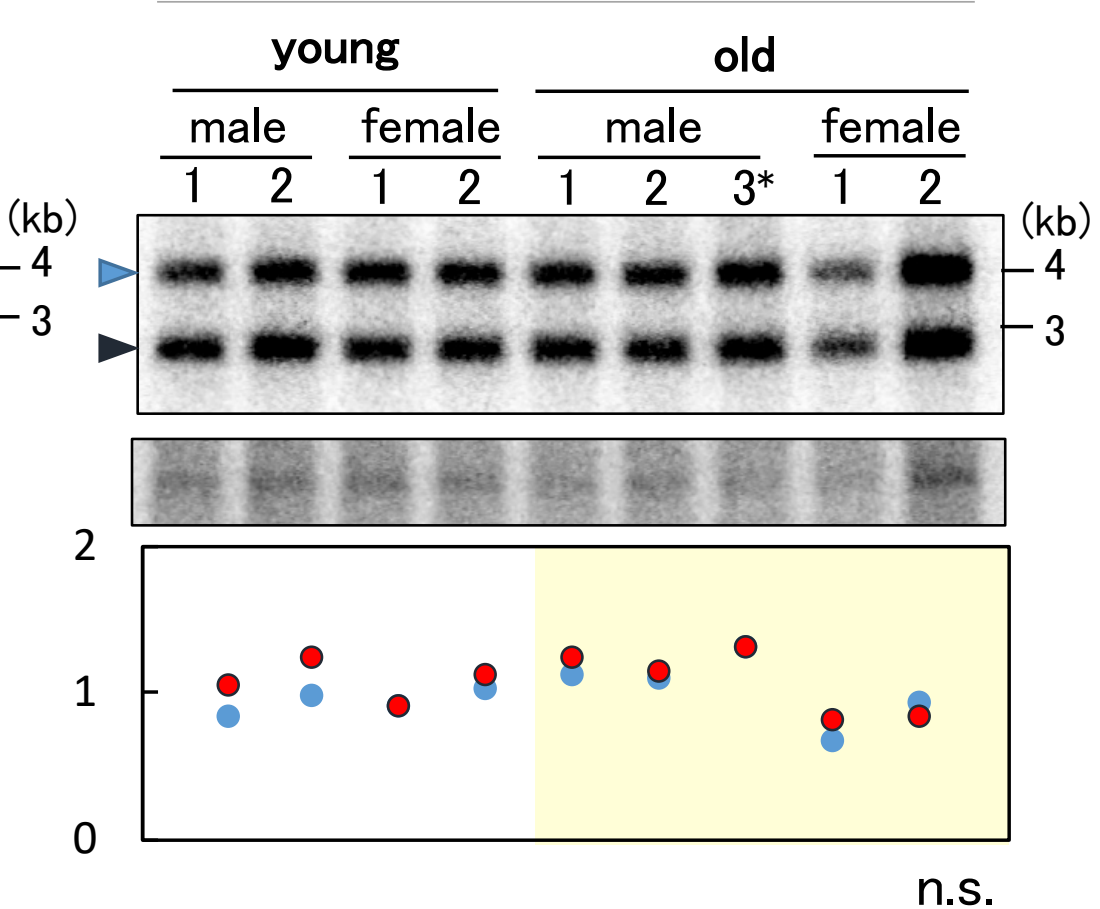

Fig.2 Detection of relative rDNA copy number in old and young mice 


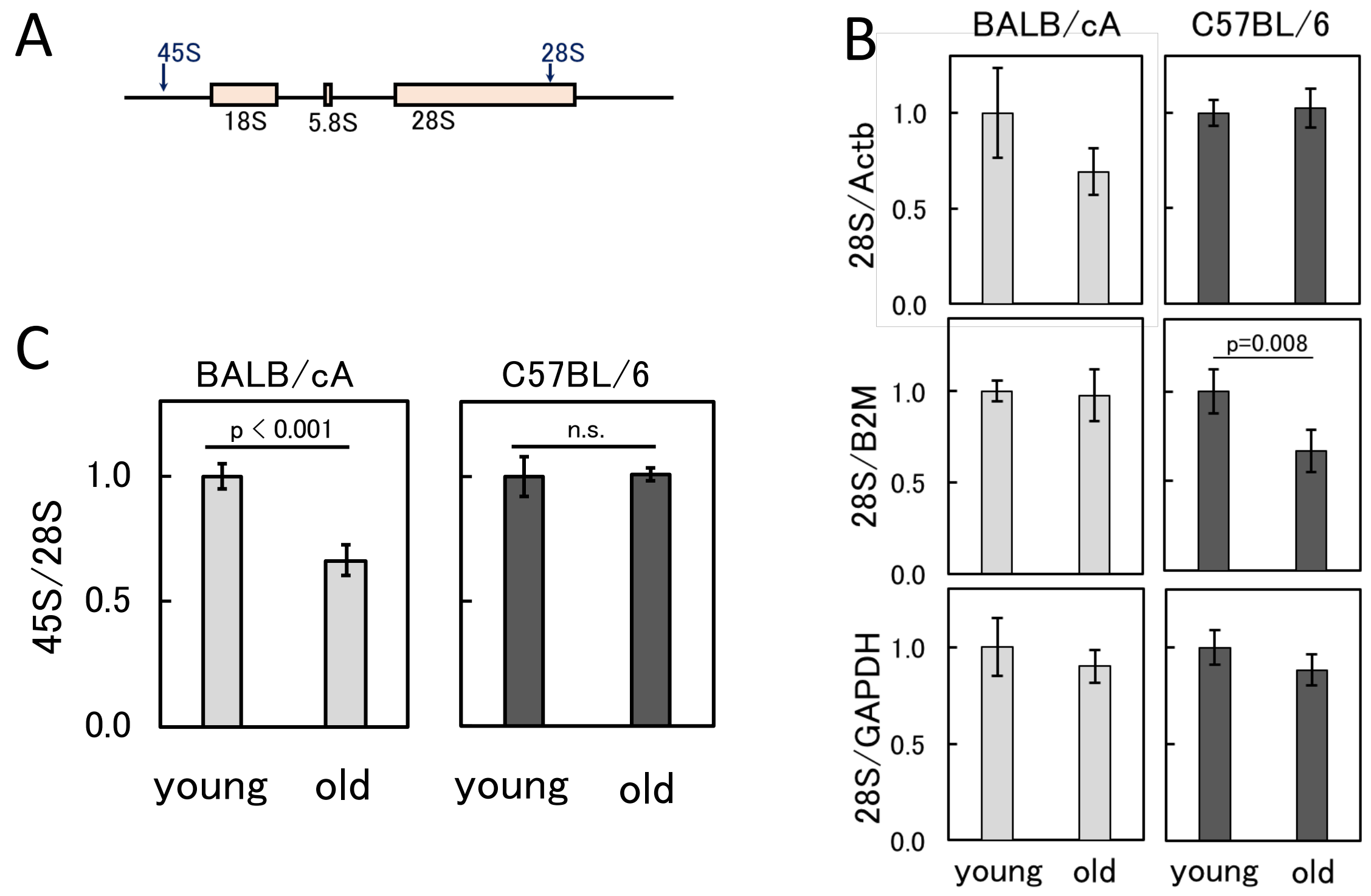

Fig.3 rDNA transcripts in old and young bone marrow cells 

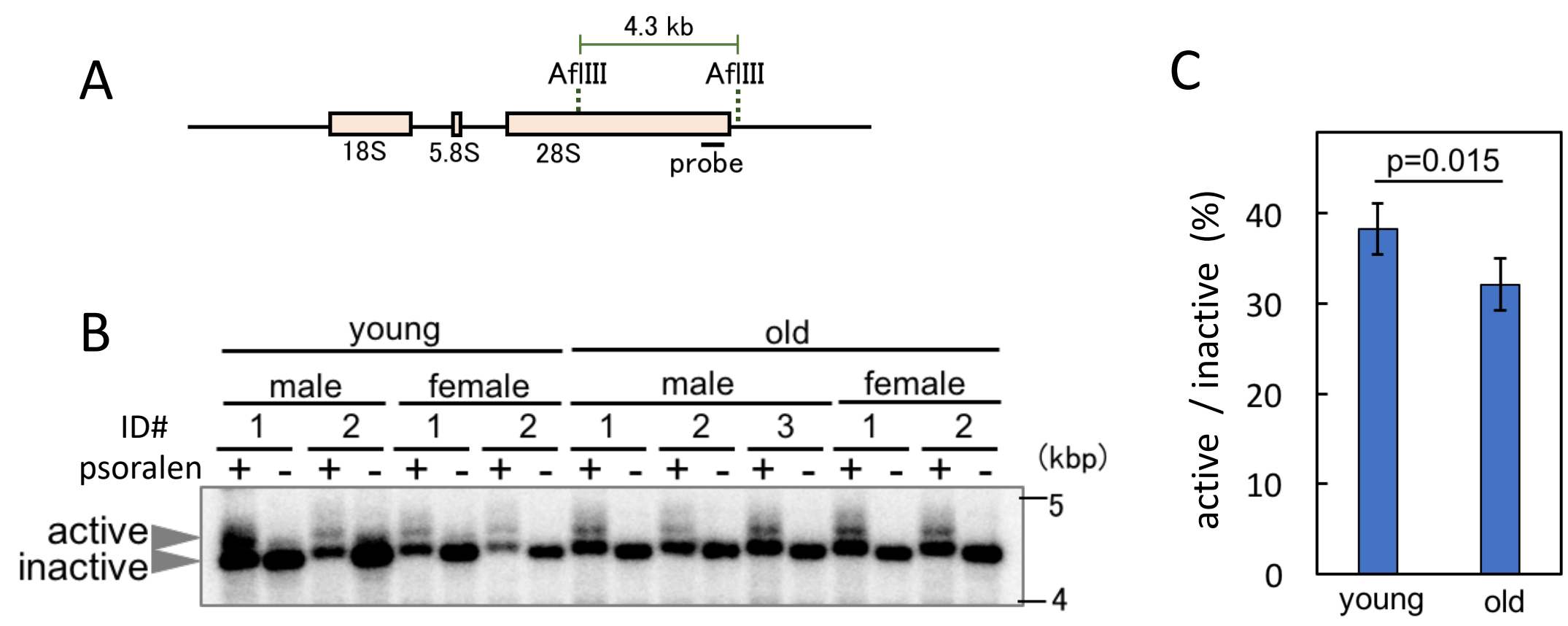

Fig.4 Ratio of active and inactive rDNA copies in old and young cells 

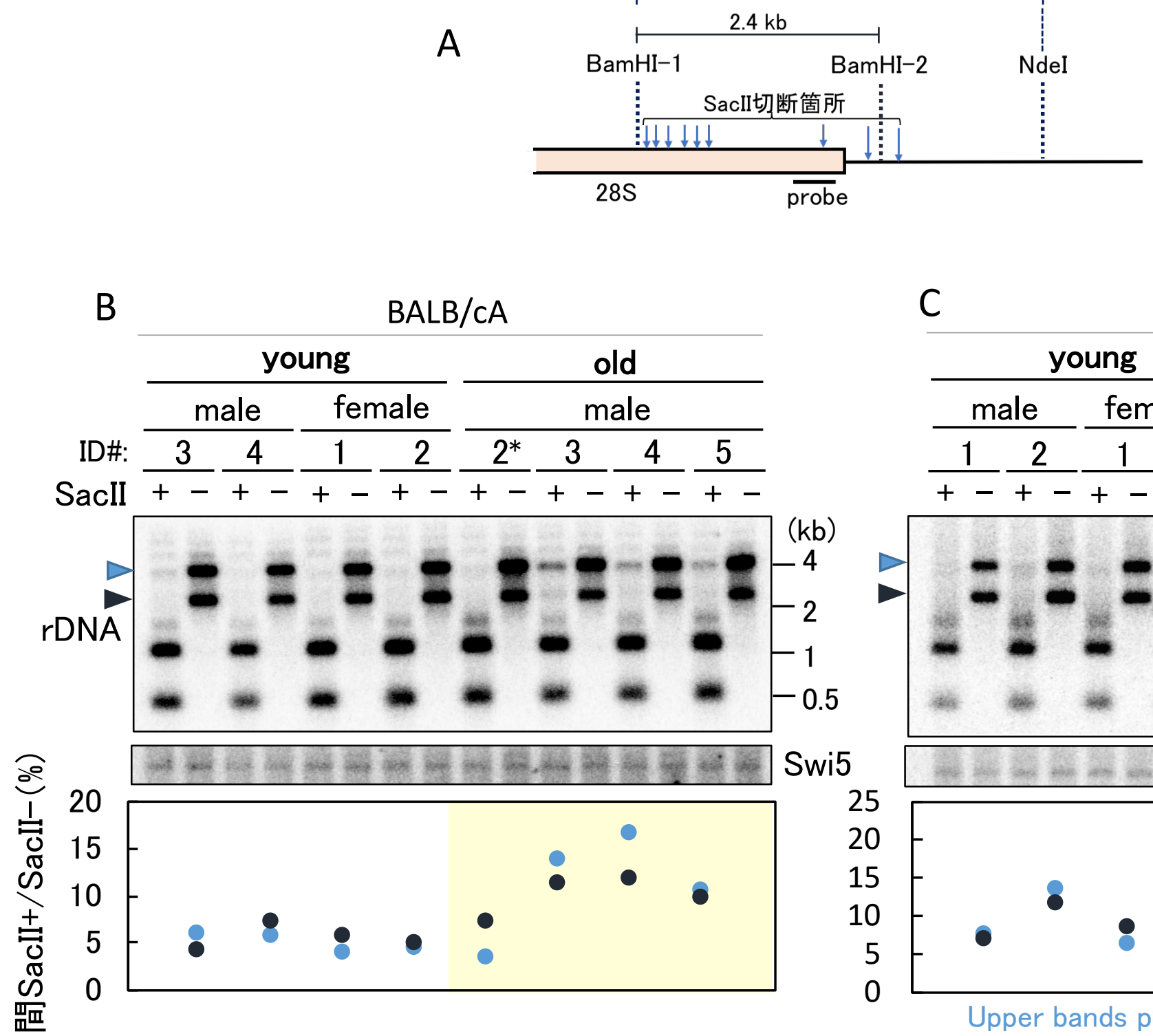

C C57BL/6
$\frac{\text { male }}{\frac{1}{+-\frac{2}{+-}} \frac{\text { female }}{+-\frac{2}{+-}}} \frac{\text { old }}{\frac{\text { male }}{1-\frac{2}{+-}} \frac{\text { female }}{+-\frac{1}{+-}}}$
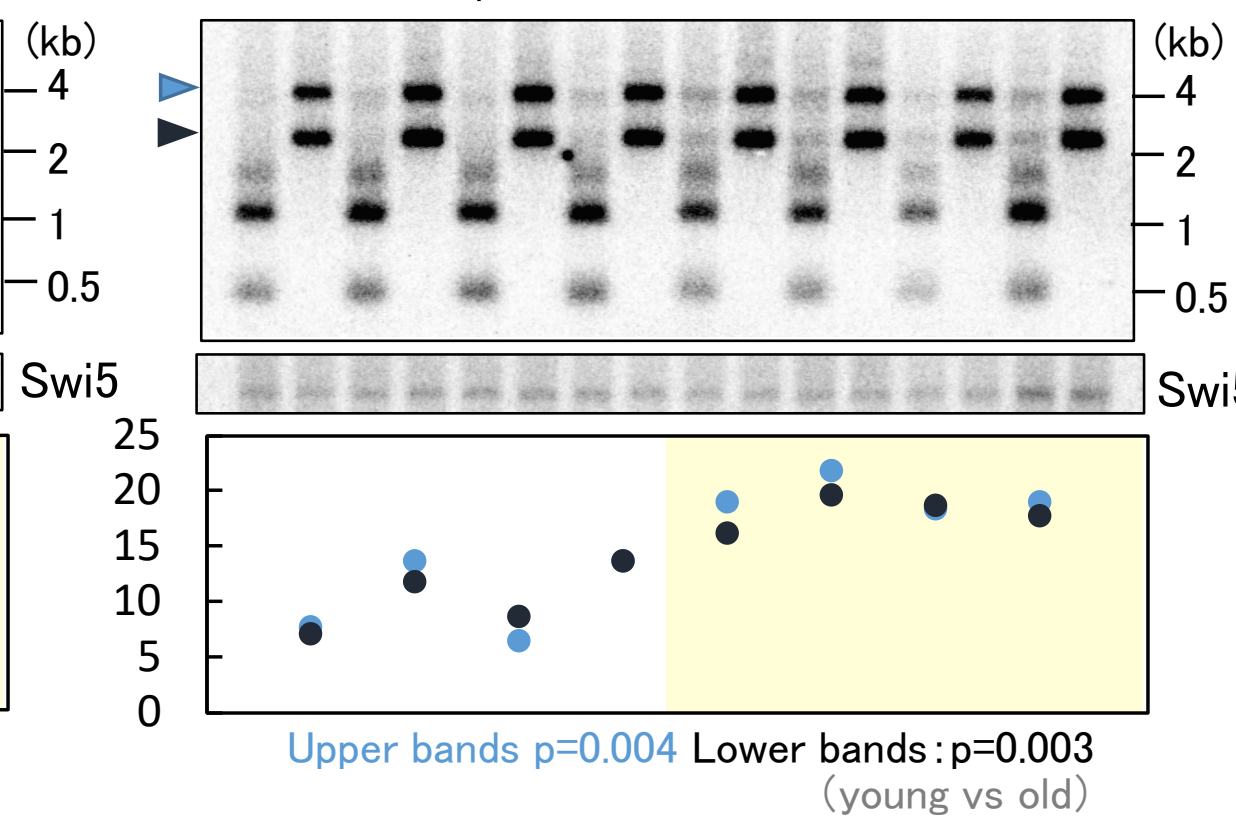

Fig.5 rDNA methylation in old and young bone marrow cells 
A 28S rRNA gene

BALB/cA (Ave. 0.00341 )

$\diamond$ young male $3 \square$ young female $1 \triangle$ old male $3 \times$ old male 4

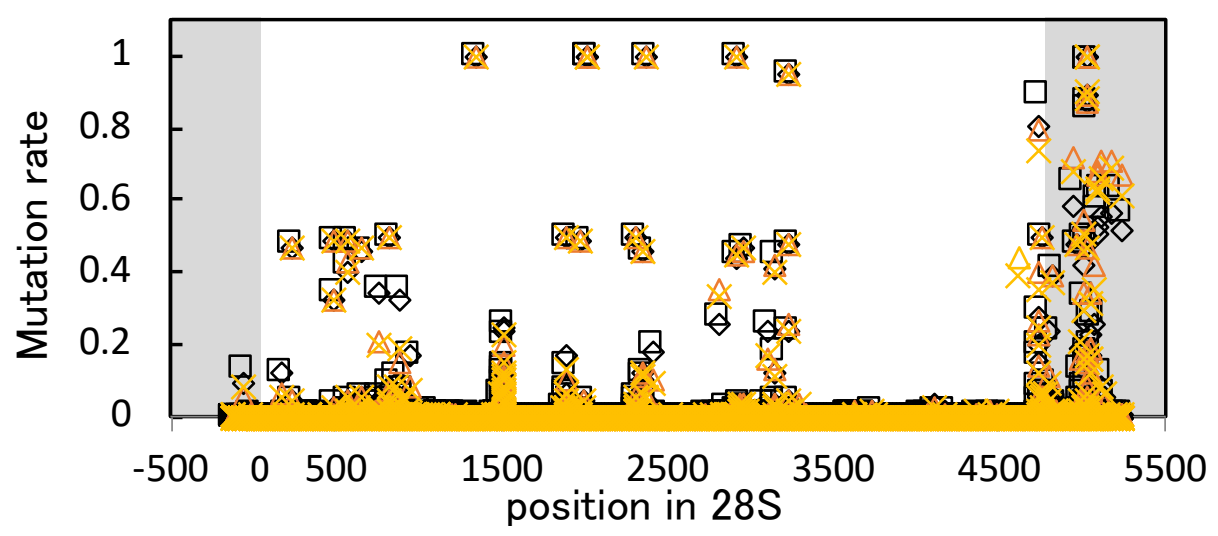

B 18S rRNA gene

BALB/cA (Ave. 0.00236 )

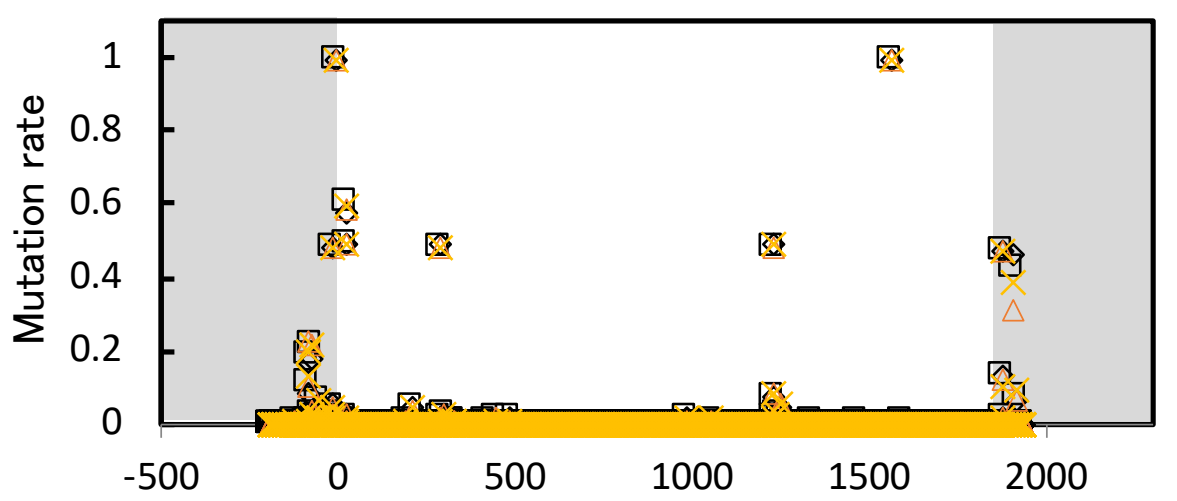

C57BL/6 (Ave. 0.00321 )

$\diamond$ young male $1 \square$ young female $1 \triangle$ old male $1 \times$ old female 1

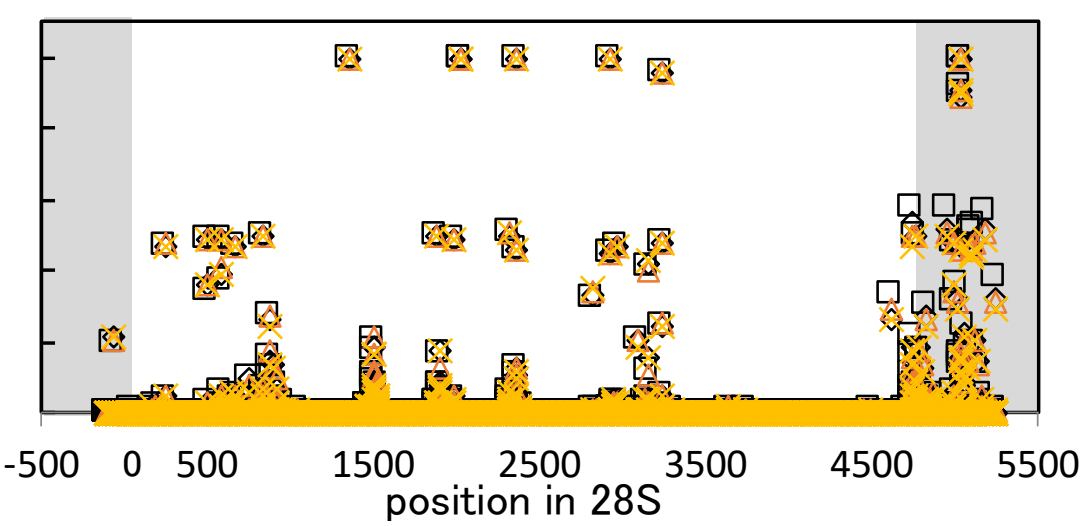

C57BL/6 (Ave. 0.00222 )

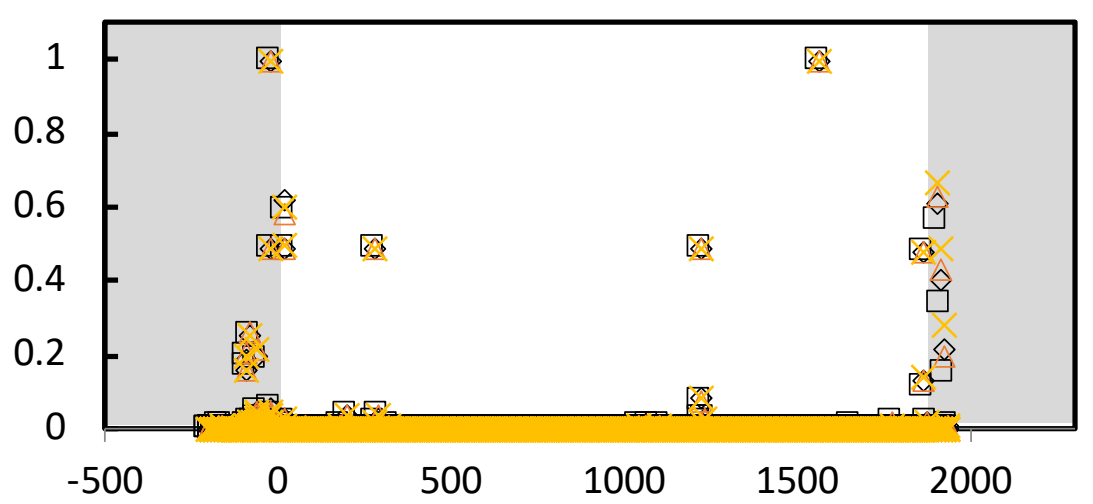

Fig.6 rDNA sequences variation in young and old mice 
C $5.8 \mathrm{~S}$ rRNA

BALB/cA (Ave.0.00064)

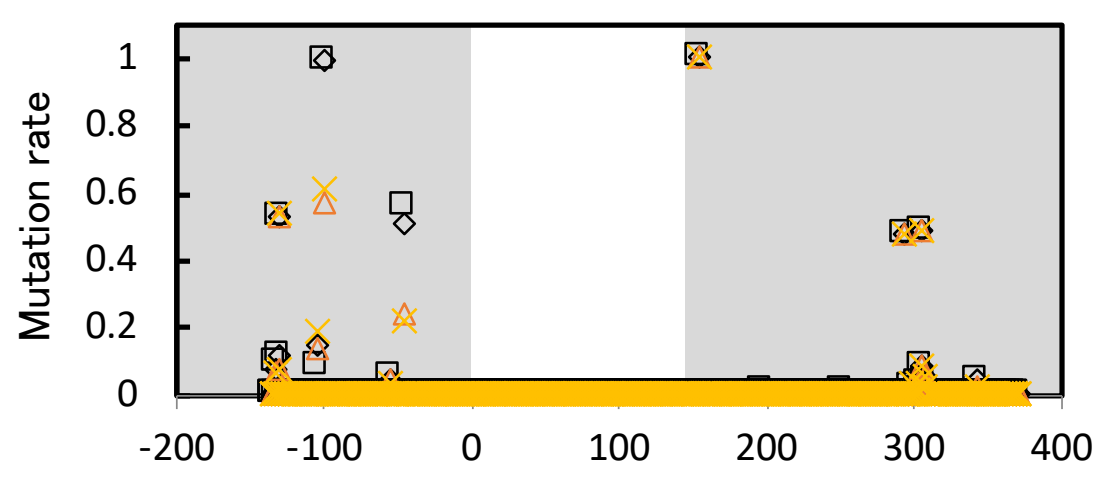

D ATP5b

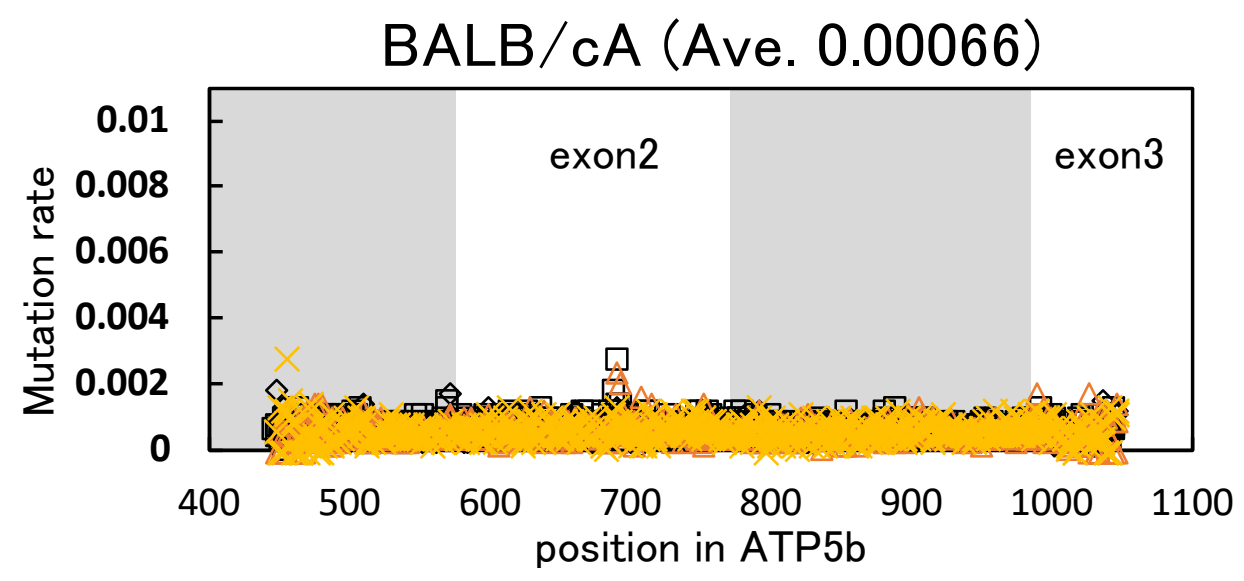

C57BL/6 (Ave. 0.00054)

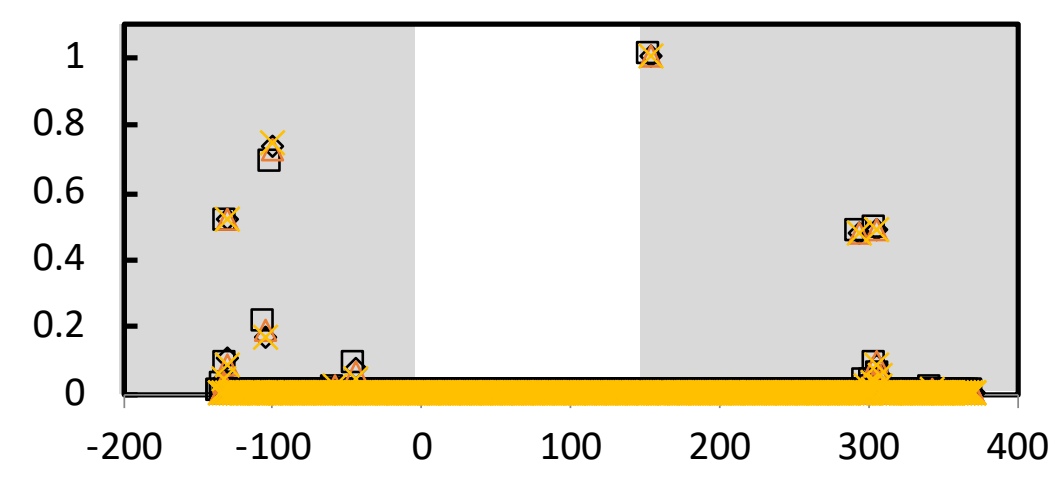

C57BL/6 (Ave. 0.00060)

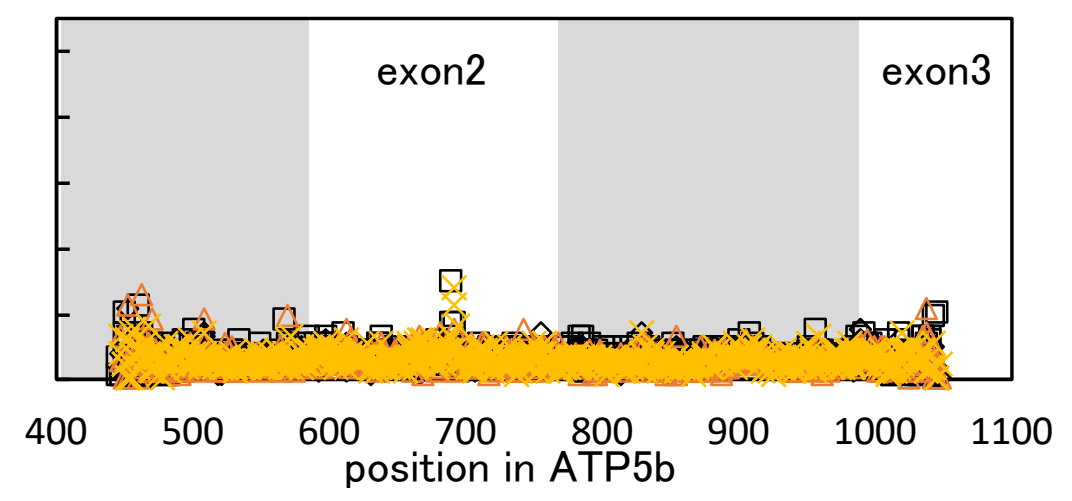




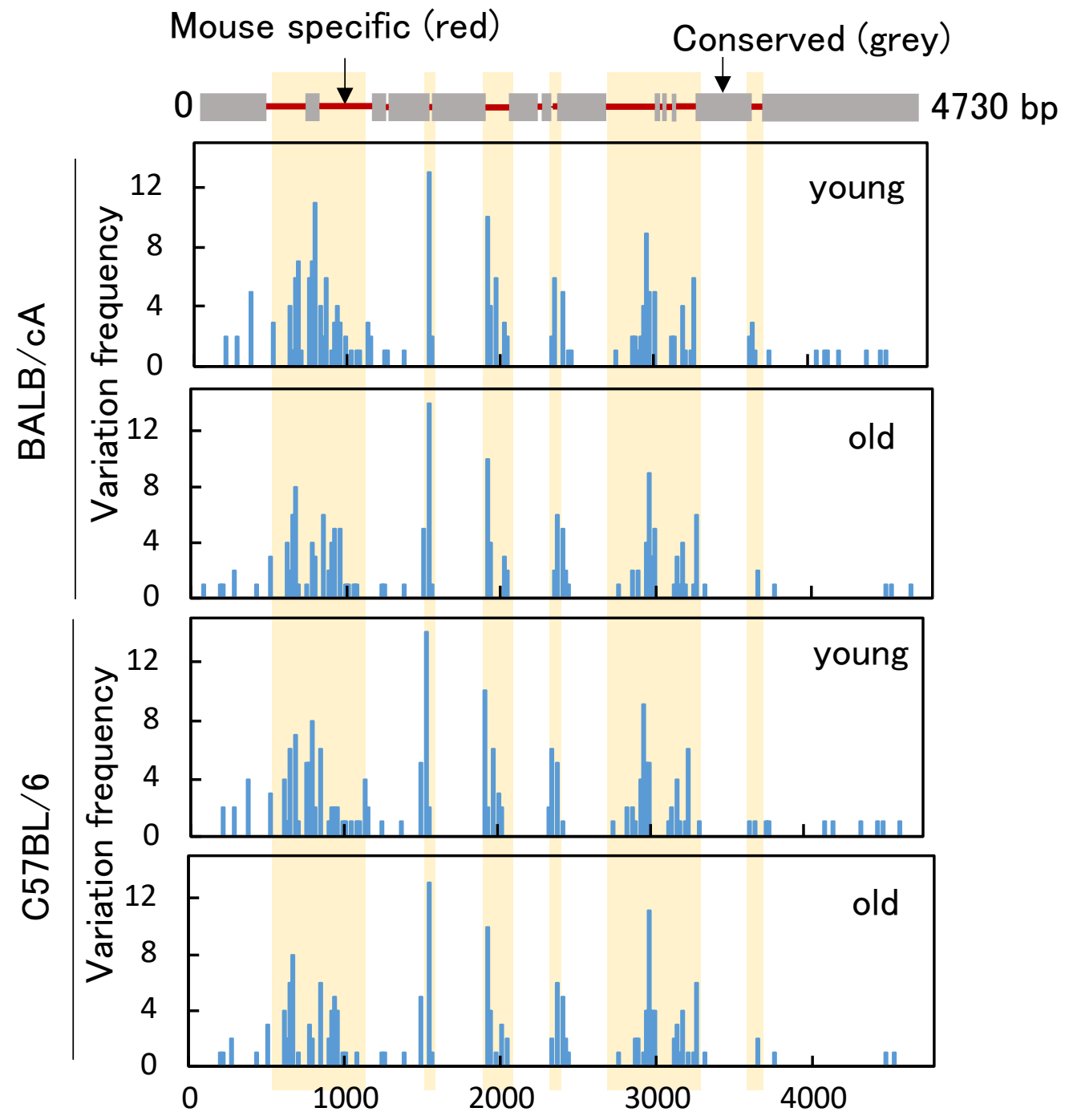

Figure 7 Hotspot of variation in the $28 \mathrm{~S}$ rDNA 

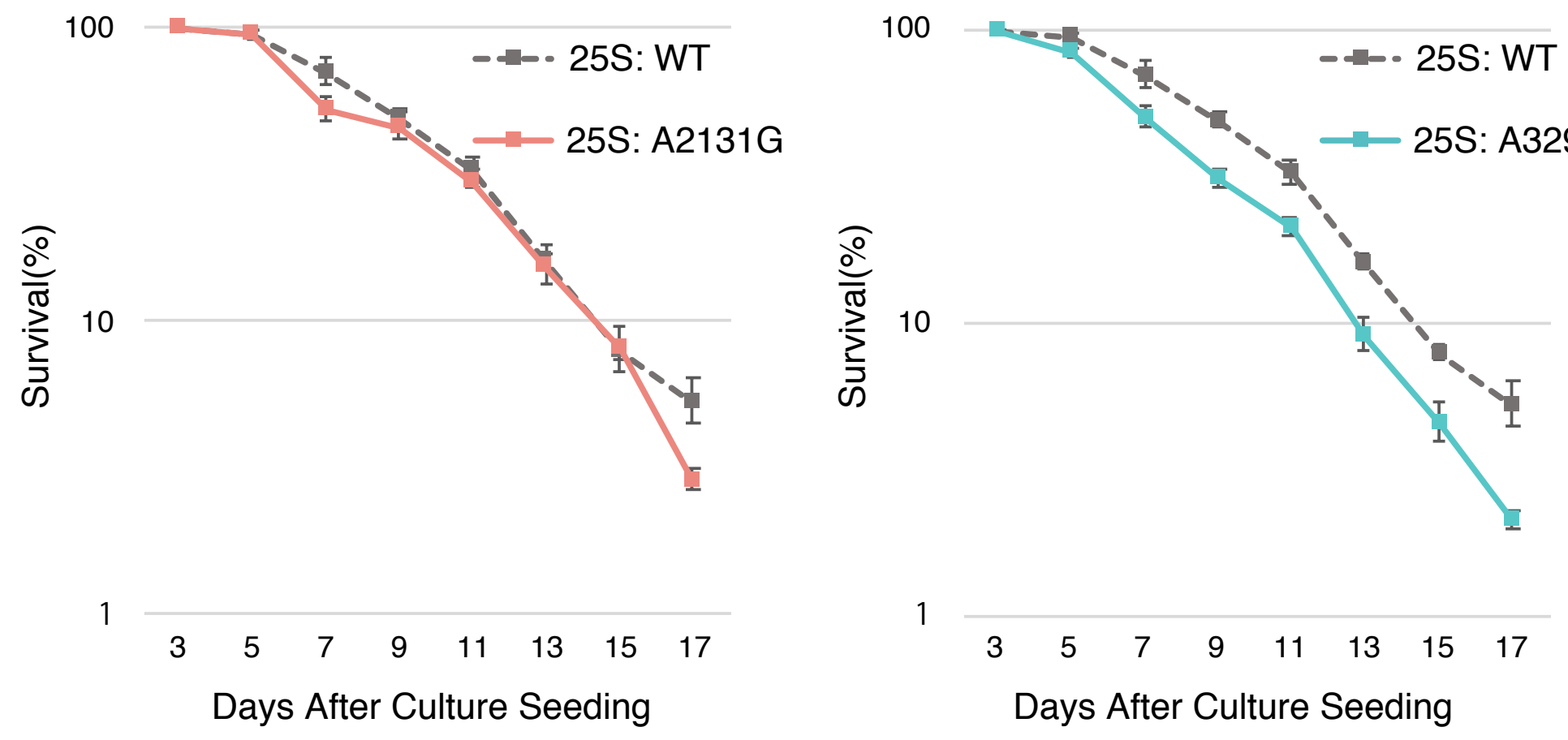

Fig.8 Chronological lifespan in budding yeast with mutated rDNA 
Table 1 The positions of old mice specific mutations in BALB/CA

\begin{tabular}{|c|c|c|c|c|c|c|c|c|}
\hline \multirow{2}{*}{$\begin{array}{c}\text { positions } \\
\text { of mouse } \\
285\end{array}$} & \multicolumn{2}{|c|}{ young } & \multirow{2}{*}{$\begin{array}{c}\text { young } \\
\text { ave. }\end{array}$} & \multicolumn{2}{|c|}{ old } & \multirow{2}{*}{ old ave. } & \multirow{2}{*}{$\begin{array}{l}\text { old - } \\
\text { young }\end{array}$} & \multirow{2}{*}{$\begin{array}{c}\text { position } \\
\text { of yeast } \\
25 \mathrm{~S}\end{array}$} \\
\hline & Male \#3 & female \#1 & & male \#3 & male \#4 & & & \\
\hline 4614 & 0.000 & 0.001 & 0.001 & 0.441 & 0.396 & 0.419 & 0.418 & 3295 \\
\hline 3291 & 0.001 & 0.001 & 0.001 & 0.039 & 0.032 & 0.035 & 0.034 & 2131 \\
\hline 3094 & 0.036 & 0.038 & 0.037 & 0.009 & 0.007 & 0.008 & -0.029 & - \\
\hline
\end{tabular}



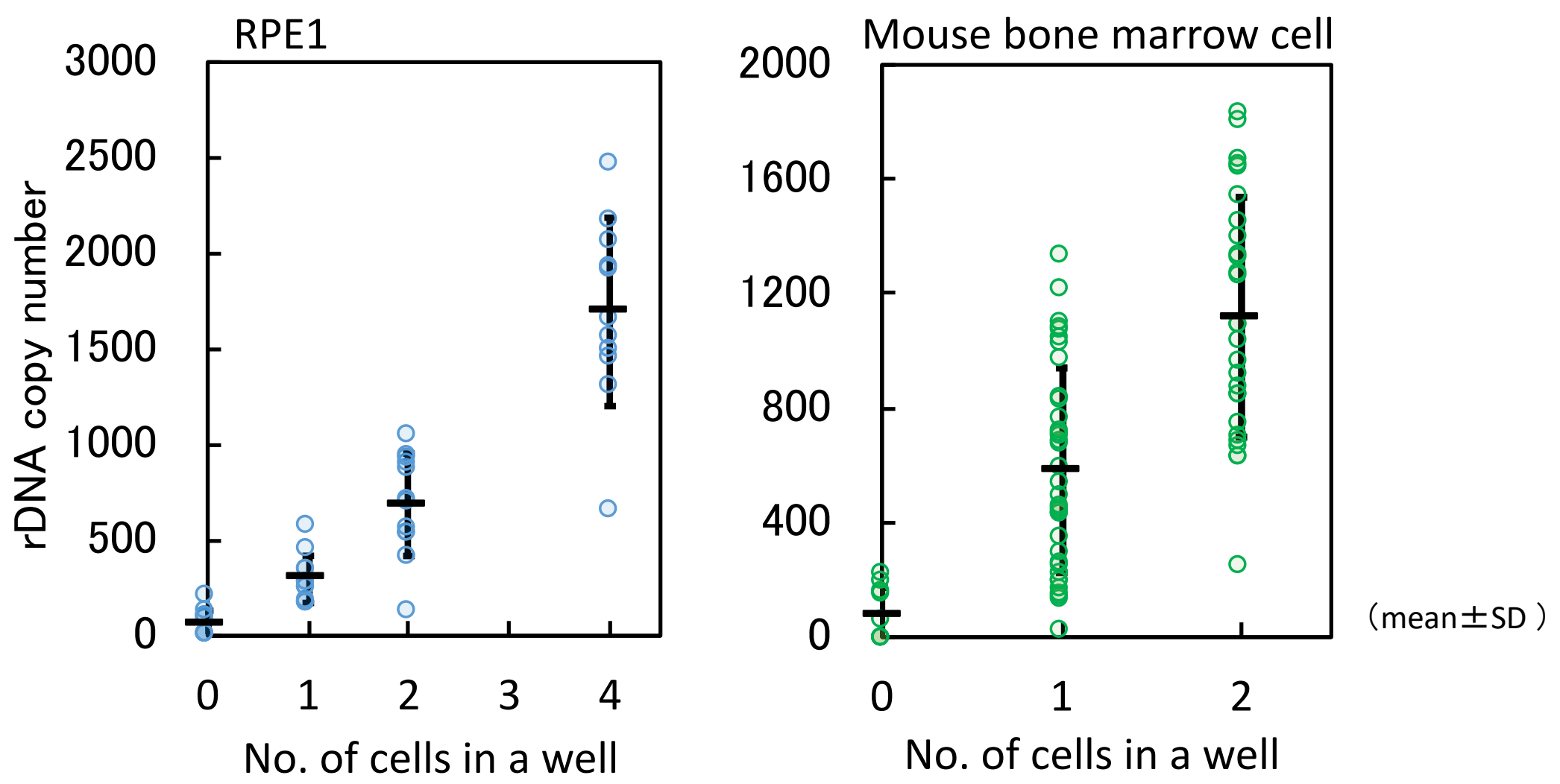

Figure S1 Accuracy in of single cell analysis 


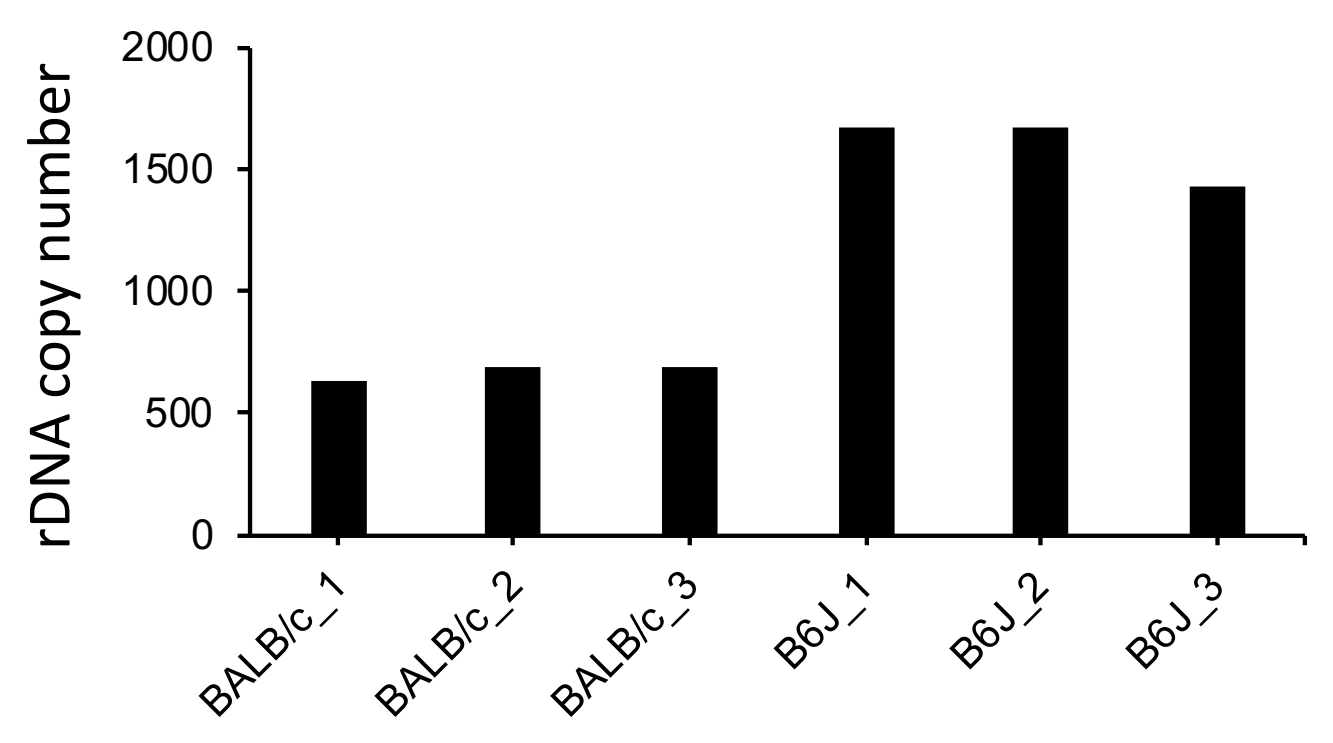

Figure S2 Estimated rDNA copy number from database 

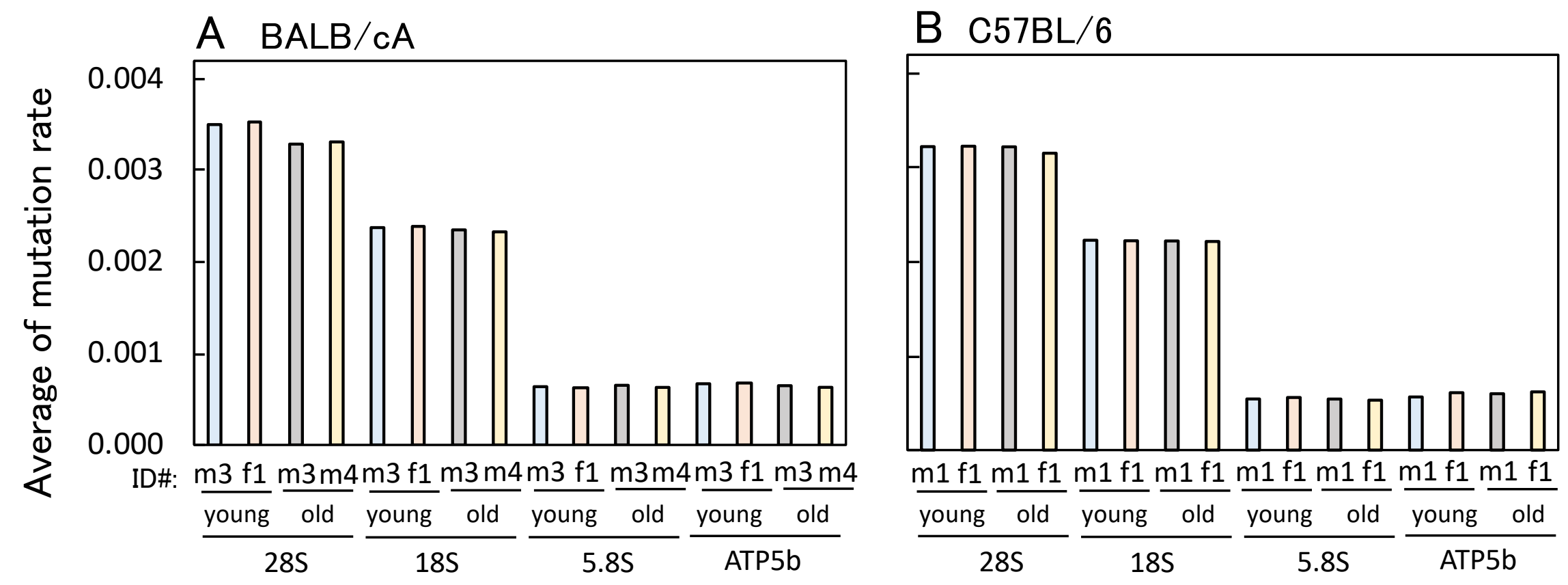

Figure S3 Mutation rates of young and old mice rDNA 


\section{A $28 \mathrm{~S}$}
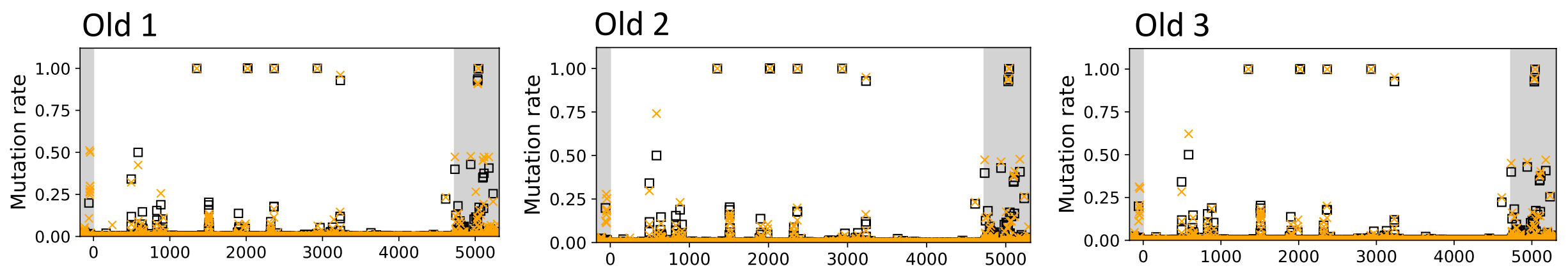

\section{B $18 \mathrm{~S}$}

\section{Old 1}
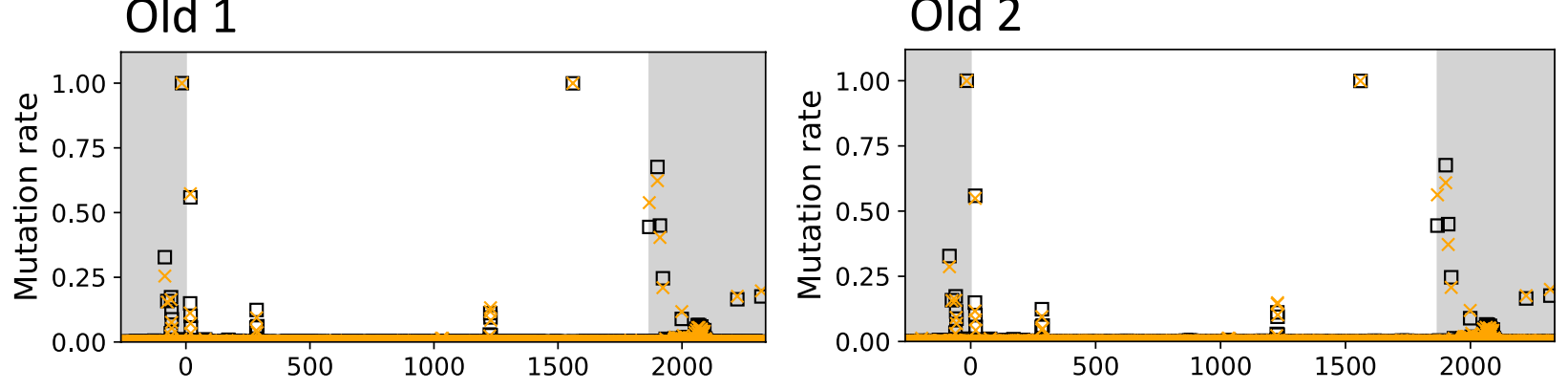

\section{C $5.8 \mathrm{~S}$}
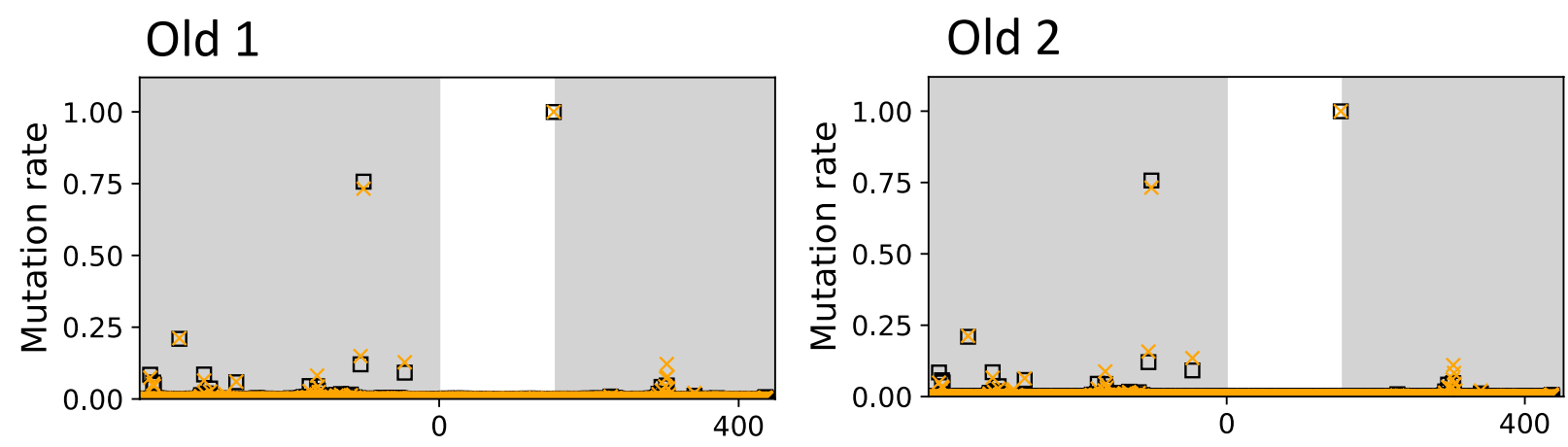
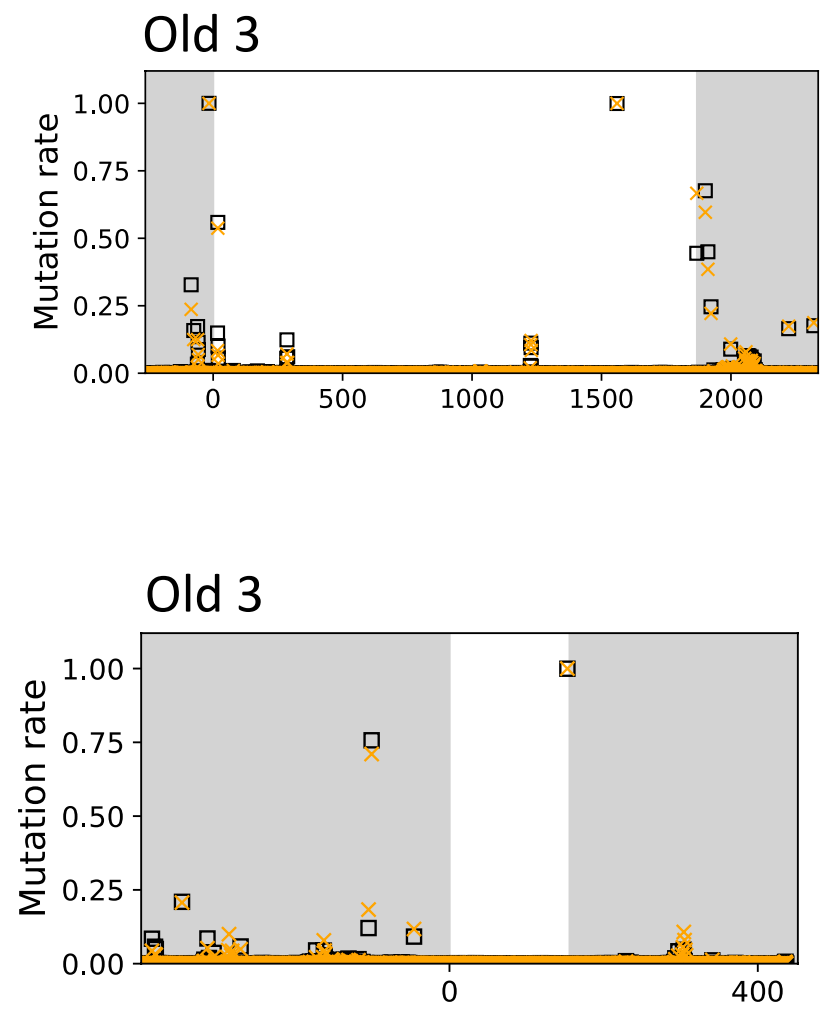

\section{Figure S4 rDNA sequence variation in young and old C57BL/6 mice}




\section{BamHI Mutated BamHI \\ 5'-GGATCC-3' $\rightarrow$ 5'-GGGGTC-3'}

\begin{tabular}{|c|c|c|c|c|}
\hline \multirow{3}{*}{$\begin{array}{c}\text { Position in } \\
28 \mathrm{~S}\end{array}$} & \multicolumn{4}{|c|}{ Mutation rate } \\
\hline & \multicolumn{2}{|c|}{ young } & \multicolumn{2}{|c|}{ old } \\
\hline & male 3 & female 1 & male 3 & male 4 \\
\hline G5050 & 0.00 & 0.00 & 0.00 & 0.00 \\
\hline G5051 & 0.00 & 0.00 & 0.00 & 0.00 \\
\hline A5052 & 0.23 & 0.27 & 0.35 & 0.32 \\
\hline T5053 & 0.00 & 0.00 & 0.19 & 0.16 \\
\hline C5054 & 0.00 & 0.00 & 0.19 & 0.16 \\
\hline C5055 & 0.00 & 0.00 & 0.00 & 0.00 \\
\hline $57 B L / 6$ & \multicolumn{2}{|c|}{ Ave: 0.25} & \multicolumn{2}{|c|}{ Ave: 0.685} \\
\hline
\end{tabular}

\begin{tabular}{|c|c|c|c|c|}
\multirow{2}{*}{$\begin{array}{c}\text { Position in } \\
2\end{array}$} & \multicolumn{4}{|c|}{ Mutation rate } \\
\cline { 2 - 5 } & \multicolumn{3}{|c|}{ young } & \multicolumn{2}{c|}{ old } \\
\cline { 2 - 5 } & male 1 & female 1 & male 1 & female 1 \\
\hline G5050 & 0.00 & 0.00 & 0.00 & 0.00 \\
\hline G5051 & 0.00 & 0.00 & 0.00 & 0.00 \\
\hline A5052 & 0.22 & 0.25 & $\mathbf{0 . 2 1}$ & $\mathbf{0 . 2 1}$ \\
\hline T5053 & 0.09 & 0.11 & $\mathbf{0 . 0 9}$ & $\mathbf{0 . 0 8}$ \\
\hline C5054 & 0.08 & 0.11 & $\mathbf{0 . 0 9}$ & $\mathbf{0 . 0 8}$ \\
\hline C5055 & 0.00 & 0.00 & 0.00 & 0.00 \\
\hline & Ave: 0.44 & Ave: 0.38 \\
\hline
\end{tabular}

Table S1 Sequence variation at BamHI recognition sequences in young and old mice. 


\begin{tabular}{|c|c|c|}
\hline Primer name & Sequence $\left(5^{\prime}\right.$ to $\left.3^{\prime}\right)$ & Note \\
\hline 28S_Fw & tgggttttaagcaggaggtg & $\begin{array}{l}\text { Figure 1, 3, } \\
\text { ddPCR }\end{array}$ \\
\hline 28S_Rv & gtgaattctgcttcacaatg & Figure 1,3 \\
\hline 28S_ddPCR_Rv & gacggtctaaacccagctca & ddPCR \\
\hline probe_28S_Fw & gttgccatggtaatcctgct & Figure $2,4,5$ \\
\hline probe_28S_Rv & acccagaagcaggtcgtcta & Figure $2,4,5$ \\
\hline probe_Swi5_Fw & aggagttgattctctctacc & Figure 2,5 \\
\hline probe_Swi5_Rv & gcatcaagacaattgtggtt & Figure 2,5 \\
\hline 45S_Fw & ctcttagatcgatgtggtgctc & Figure 3 \\
\hline 45S_Rv & gcccgctggcagaacgagaag & Figure 3 \\
\hline Actb_Fw & gacggccaggtcatcactattg & Figure 3 \\
\hline Actb_Rv & agtttcatggatgccacagg & Figure 3 \\
\hline GAPDH_Fw & actcacggcaaattcaacgg & Figure 3 \\
\hline GAPDH_Rv & atgttagtggggtctcgctc & Figure 3 \\
\hline B2M_Fw & tacgtaacacagttccaccc & Figure 3 \\
\hline B2M_Rv & tgctgaaggacatatctgac & Figure 3 \\
\hline 18S_Seq_Fw & taagagaggtgtcggagagc & Figure 6 \\
\hline 18S_Seq_Rv & cttctctcacctcactccag & Figure 6 \\
\hline 5.8S_Seq_Fw & gtcgttcccgtgtttttccg & Figure 6 \\
\hline 5.8S_Seq_Rv & gaccgagaaagactggtgag & Figure 6 \\
\hline 28S_Seq_Fw & ggttgcgtgtgagtaagatcctc & Figure 6 \\
\hline 28S_Seq_Rv & tactggtcgacctccgaagttg & Figure 6 \\
\hline ATP5b_Seq_Fw & gaataatggcggttctgtgcac & Figure 6 \\
\hline ATP5b_Seq_Rv & atgattctgcccaaggtctcag & Figure 6 \\
\hline 28S_target_probe & 6FAM-gccgacatcgaaggatcaaaaagcgac-BHQ1 & ddPCR \\
\hline
\end{tabular}

\section{Table S2 Primer list}

